\title{
DR. 1035
}

DEVELOPMENT OF ECONOMICAL IMPROVED THICK FILM SOLAR CELL
CONTACT

Quarterly Report No. 3 for May-July 1979

By

Bernd Ross

August 1979

Work Performed Under Contract No. NAS-7-100-955164

Bernd Ross Associates

San Diego, California

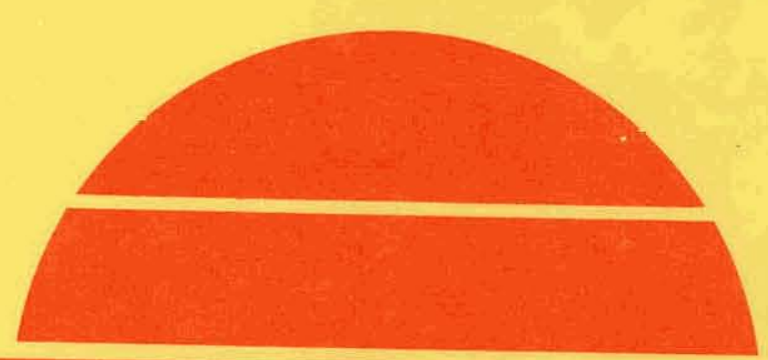

\section{U.S. Department of Energy}

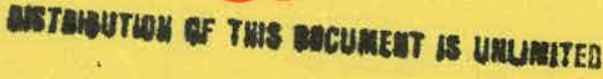

Solar Energy 


\section{DISCLAIMER}

This report was prepared as an account of work sponsored by an agency of the United States Government. Neither the United States Government nor any agency Thereof, nor any of their employees, makes any warranty, express or implied, or assumes any legal liability or responsibility for the accuracy, completeness, or usefulness of any information, apparatus, product, or process disclosed, or represents that its use would not infringe privately owned rights. Reference herein to any specific commercial product, process, or service by trade name, trademark, manufacturer, or otherwise does not necessarily constitute or imply its endorsement, recommendation, or favoring by the United States Government or any agency thereof. The views and opinions of authors expressed herein do not necessarily state or reflect those of the United States Government or any agency thereof. 


\section{DISCLAIMER}

Portions of this document may be illegible in electronic image products. Images are produced from the best available original document. 


\section{DISCLAIMER}

"This book was prepared as an account of work sponsored by an agency of the United States Government. Neither the United States Government nor any agency thereof, nor any of their employees, makes any warranty, express or implied, or assumes any legal liability or responsibility for the accuracy, completeness, or usefulness of any information, apparatus, product, or process disclosed, or represents that its use would not infringe privately owned rights. Reference herein to any specific commercial product, process, or service by trade name, trademark, manufacturer, or otherwise, does not necessarily constitute or imply its endorsement, recommendation, or favoring by the United States Government or any agency thereof. The views and opinions of authors expressed herein do not necessarily statc ur reflect those of the United States Government or any agency thereof."

This report has been reproduced directly from the best available copy.

Available from the National Technical Information Service, U. S. Department of Commerce, Springfield, Virginia 22161.

Price: Paper Copy $\$ 7.00$ Microfiche $\$ 3.50$ 


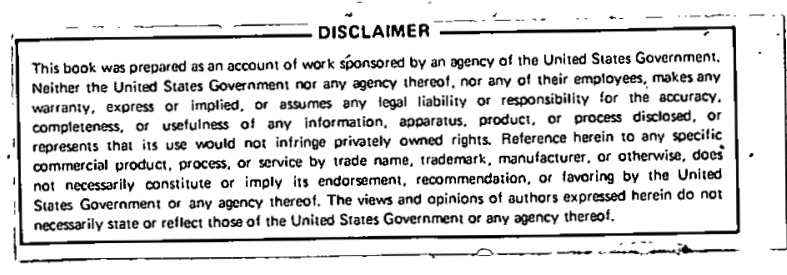

\title{
DEVELOPMENT OF ECONOMICAL IMPROVED THICK FILM SOLAR CELL CONTACT
}

\author{
BERND ROSS \\ BERND ROSS ASSOCIATES \\ 2154 Blackmore Ct. \\ San Diego, CA 92109
}

\author{
QUARTERLY REPORT NO. 3 \\ PERIOD COVERED \\ May - July 1979
}

August 1979

Contractual Acknowledgment

The JPL Low-Cost Silicon Solar Array Project is sponsored by the U.S. Department of Energy and forms part of the Solar Photovoltaic Conversion Program to initiate a major effort toward the development of low-cost solar arrays. This work was performed for the Jet Propulsion Laboratory, California Institute of. Technology by agreement between NASA and DOE. 
THIS PAGE

\section{WAS INTENTIONALLY \\ LEFT BLANK}


TABLE OF CONTENTS

Page

LIST OF FIGURES

HIST OF FIGURES

iv

1.0 SUMMARY

2.0 INTRODUCTION 2

3.0 SERIES AND CONTACT RESISTANCE CONSIDERATIONS 3

1. Contact Resistance Measurement Method 6

2. Contact Resistance Measurement Results 8

4.0 METAL SYSTEMS CONSIDERATIONS 13

1. Fabrication of Germanium-Antimony Eutectic

Powder
2. Analysis of Hydrogen Fired Silver Inks

3. Analysis of Electrical Characteristics

4. Survey of Binary Alloys of Silver, Nickel and Copper

5.0 METAL PASTE PREPARATTNNS 33

6.0 CONCLUSIONS AND PROBLEMS 34

7.0 PLANS . 36

8.0. PROGRESS ON PROGRAM PLAN

9.0 APPENDIX $\quad 39$

A.1 Contact Resistance Data and Sample Calculation 40

A.2 IV Curves of Hydrogen Fired Silver Inks 42

A.3 Additional Phase Diagrams of the Nickel, Copper and Silver Systems

A. 4 Milling Procedure For A11 Metal Pastes 54

$\begin{array}{lll}10.0 & \text { BIBLIOGRAPHY } & 57\end{array}$ 
1 Simple Resistance - Contact Resistance Measurement

Series Resistance Measurement by Illumination Level Change

Metal Semiconductor Contact (Shockley's Method)

Masks For Contact Resistance Measurement

Screened Contact Pattern (Green)

Screened Contact Pattern (Fired)

SEM Photomicrograph of Peeled $\mathrm{H}_{2}$ Fired Print $\mathrm{S} 034$ at $200 \mathrm{X}$

SEM Photomicrograph of Peeled $\mathrm{H}_{2}^{2}$ Fired Print S034 at $1000 \mathrm{X}$

SEM Photomicrograph of Peeled $\mathrm{H}_{2}^{2}$ Fired Print 5034 at $5,000 \mathrm{X}$

SEM Photomicrograph of Peeled $\mathrm{H}_{2}^{2}$. Fired Print S034 at $10,000 \mathrm{X}$

SEM Photomicrograph of Peeled $\mathrm{H}_{2}^{2}$ Fired Print 5063 at $510 \mathrm{X}$

SEM Photomicrograph of Peeled $\mathrm{H}_{2}^{2}$ Fired Print $\mathrm{S} 063$ at 5,100X

SEM Photomicrograph of Peeled $\mathrm{H}_{2}^{2}$ Fired Print 5059 at $1000 \mathrm{X}$

SEM Photomicrograph of Peeled $\mathrm{H}_{2}^{2}$ Fired Print S059 at 5,000X

SEM Photomicrograph of Peeled $\mathrm{H}_{2}^{2}$ Fired Print S059 at 10,000X

Equilibrium Phase Diagram of Silver-Lead System

Solubility Curve of Silver-Lead System

Equilibrium Phase Diagram of Nickel-Tin System

Solubility Curve of Nickel-Tin System

Equilibrium Phase Diagram of Nickel-Lead system

Solubility Curve of Nickel-Lead System

Equilibrium Phase Diagram of Nickel-Silicon System

Equilibrium Phase Diagram of Copper-Lead System

Solubility Curve of Copper-Lead System

Equilibrium Phase Diagram of Copper-Silicon System

Sample Plot \& Contact Resistance Calculation (Appendix)

Sample Plot \& Contact Resistance Calculation (Appendix)

Raw IV Curves Control Cells $600^{\circ} \mathrm{C}-10^{\circ} \mathrm{min} . \mathrm{H}_{2}$

Raw IV Curves S063 (Textured)

Raw IV Curves S063

Raw IV Curves 5064

Raw IV Curves S064
Raw IV Curves Control Cells (Tex.) 65

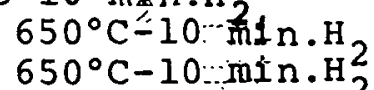

$650^{\circ} \mathrm{C}-10 \ldots \mathrm{min} . \mathrm{H}_{2}^{2}$

$650^{\circ} \mathrm{C}-10$. min. $\mathrm{H}_{2}^{2}$

$\begin{array}{lll}\text { Raw IV Curves S064 (Front) } 650^{\circ} \mathrm{C}-10 \mathrm{~min} . \mathrm{H} & \\ \text { Raw IV Curves S064 (Front-Textured) } 600^{\circ} \mathrm{C}-10 \mathrm{~min} \text {. }\end{array}$

$650^{\circ} \mathrm{C}-10 \mathrm{m \pm n} . \mathrm{H}_{2}^{2}$

Equilibrium Phase Diagram of Nickel-Antimony System

Equilibrium Phase Diagram of Nickel-Zinc System

Equilibrium Phase Diagram of Nickel-Bismuth System

Equilibrium Phase Diagram of Copper-Zinc System

Equilibrium Phase Diagram of Copper-Aluminum System

Equilibrium Phase Diagram of Copper-Germanium System

Equilibrium Phase Diagram of Copper-Antimony System

Table

Equilibrium Phase Diagram of Copper-Tin System

1 Electrical Results of Solar Cell Tests with S063 and S064 
Various measurement methods of series resistance and specific contact resistance were considered: Several attempts were made to produce eutectic alloys in air and in neutral (nitrogen) atmospheres, but the resulting product was not considered satisfactory. A commercial source of eutectic aluminum-silicon and aluminum-germanium was located. Fifteen all metal pastes were fabricated during this reporting period including 12 base metal pastes. Silver inks fired in hydrogen were non-adherent. Electrical results of screened solar celi tests were poor, indicating diffused layer penetration. Similar results occurred with titanium-palladium-silver controls. A survey was made of alloys containing nickel and copper. Solubilities of nickel, silver and copper in various low melting metals were calculated from the phase diagrams and plotted. An ink milling procedure was written for all metal inks. Base metal powders were ordered and partially received. A tube furnace was purchased and installed, along with ja gas handling system, designed for hydrogen and nitrogen firing. 
The potential for economy and efficiency has been demonstrated for the thick film metallization process using screen printing for solar cell electrodes. However, process reliability and materials economy remain deficient. It is believed that these deficiencies can be removed by the use of ink formulations designed specifically for silicon solar cells, departing from ceramic technology tradition and utilizing all metal systems. The objectives of this investigation are as follows:

1. Eliminate the glass frit which has been the conventional liquid phase sintering medium and adhesive for metallization inks.

2. Provide an appropriate metal which can serve as the . liquid phase sintering medium.

3. Find a chemical constituent which effectively removes the native oxide from the silicon during the firing step, which can be made part of the ink, and which either becomes fugitive or remains an inert part of the matured metallization.

4. Maintain cognizance of the cost objectives of the LSA Project in selecting materials and processes. 
The measurement of contact resistance has been somewhat problematical since the work with thick film electrodes began." Several methods have been utilized in the past using either silicon material or solar celis as a point of departure. A relatively simple method uses a silicon rod of simple shape shown in Figure 1. The resistivity of the rod is determined by other means (such as a four point probe). The resistance of the rod and contacts is measured across the two electrodes: The contact resistance is

$$
\begin{aligned}
\mathrm{R}_{\mathrm{C}}=\mathrm{R}^{\mathrm{R}}-\mathrm{L} & = \\
\text { where } \mathrm{R} & =\text { total resistance in } \Omega \\
\rho & =\text { resistivity of the } \\
& \text { silicon material in } \Omega \mathrm{cm} \\
\mathrm{L} & =\text { length of rod in } \mathrm{cm} \\
\mathrm{A} & =\text { area of contact in } \mathrm{cm}^{2}
\end{aligned}
$$

While the method has the virtue of analytical simplicity, it is experimentally somewhat cumbersome and requires resistivity determination prior to attaching contacts, with no guarantee that the resistivity remains unchanged as a function of the firing process. In our measurements the series resistance between two adjacent squares of a screened standard pattern was used. The actual current flux pattern in such a configuration is complex and can be handled by using the formalism of source and sink images ${ }^{l}$. For our purposes an average current path was estimated, the resistivity of the wafers was in a fairly tight group and only relative measure- 
ments were required. Nevertheless, the variation in results and reproducibility problems caused us to lose confidence in the method.

In dealing with diodes or solar cells, contact resistance is a part of the series resistance, including IR drops of semiconductor regions and electrode regions themselves. While some of these can be measured with difficulty, assumptions as to their magnitude are usually made. The series resistance can then be determined from an extended IV curve (log I versus V) by noting the departure from the exponential diode characteristic ${ }^{2}$. Another method utilizes multiple light levels with series resistance measured by taking incremental currents and noting the shift in corresponding terminal voltage $^{3}$. (See Figure 2). None of the above methods were considered optimal for this investigation.: Therefore, a literature study was undertaken to find a better method. 
L

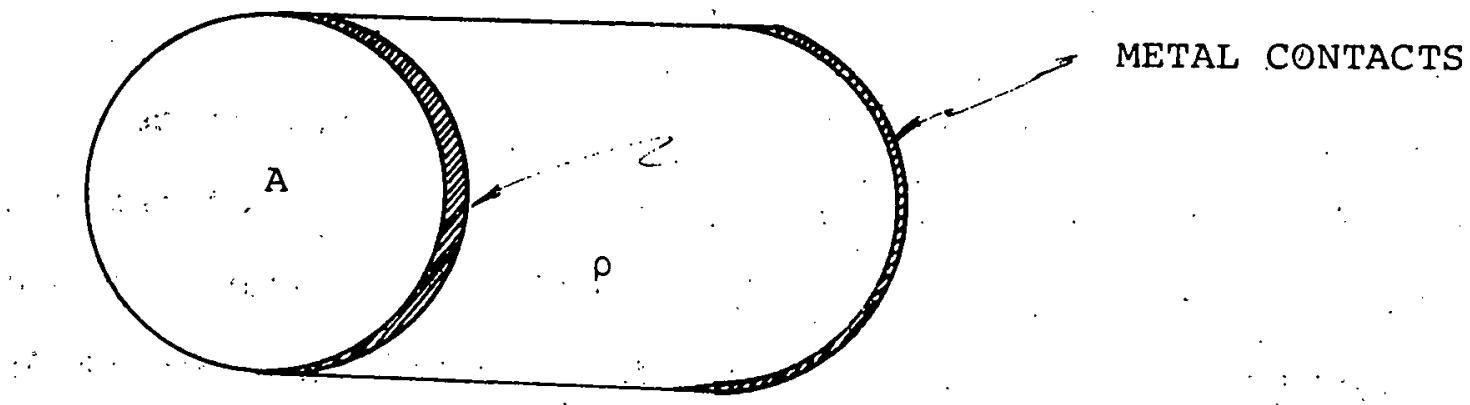

Fig. 1. Simple Resistance - Contact Resistance Measurement.

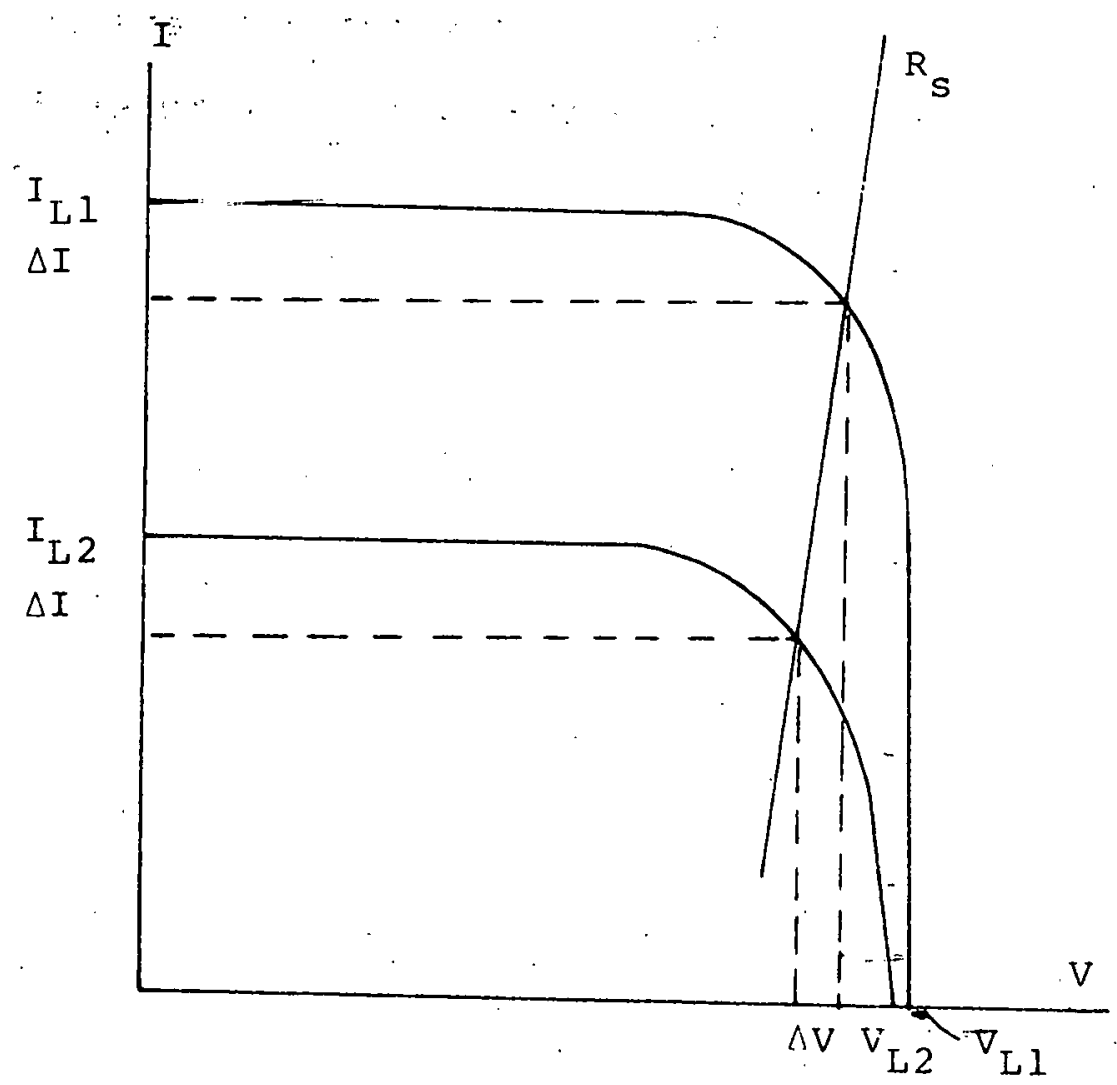

Fig. 2. Series Resistance Measurement by Illumination Level Change

(L. D. Swanson's Method) 
A reference was found to a contact resistance measurement proposed by $W$. Shockley. The method was designed to accommodate field effect transistors and was described by Hower et al 4 . The measurement scheme is well-suited to contact resistance evaluation of electrodes or electrode arrays on solar cell material prior to cell processing, pn-junction formation, etc. Since the existence of a conducting sheet on the opposite side of the wafer would severely aiter the current flux densities and contours, the test would be less suitable for completed solar cells. While the dimensions of the semiconductor layer and electrodes are quite different in the case of the solar cell experiments from the original FET designs, there are no fundamental reasons why the measurement should not work for our purposes. The method can best be illustrated by Figure 3 . Figure 3 (a) shows a contact metal layer on a semiconductor wafer with dimensions $\mathbf{x}$ and $\mathbf{z}$ (with $y$ dimension arbitrary). The schematic (b) below (a) considers the semiconductor a chain of sheet resistances $R_{\square}$ (in units of ohms per square) connected to the grounded metal contact by contact resistances $R_{c}$ in ladder network fashion. Since the metal resistance is very small compared to the other resistances involved, it may be neglected in this formulation. The current I flowing through the semiconductor wafer enters the region below the metal contact at $x=0$. A portion of the current, $\Delta I$ enters the electrode through $R_{C}$ and diminishes the wafer current $I$. This 
results in a potential distribution $\mathrm{V}(\mathrm{x})$ given by figure $3(\mathrm{c})$. The differential equation describing the stated conditions is

$$
\frac{R_{c}}{R_{a}} \frac{d^{2} v(x)}{d_{x}^{2}}-v(x) d x=.0
$$

with solution

$$
\begin{aligned}
& \mathrm{V}(\mathrm{x})=\mathrm{V}_{0} \exp \left(-\frac{\mathrm{x}}{\mathrm{L}_{\mathrm{T}}}\right) \\
& \text { where } \mathrm{L}_{\mathrm{T}} \equiv \operatorname{Transfer} \text { length } \\
&=\sqrt{\mathrm{R}_{\mathrm{C}} / \mathrm{R}_{\mathrm{D}}}
\end{aligned}
$$

All other quantities were previously defined. 
The method was reduced to practice by designing masks shown in Figure 4. The current source and drain contacts were squares of $2.5 \mathrm{~mm}$ edge length spaced to allow potential probe contacts to be placed at equal intervals between them. The small contacts were $0.25 \mathrm{~mm}$ wide, $0.6 \mathrm{~mm}$ long and placed on $0.5 \mathrm{~mm}$ centers. Separate masks were fabricated so that current and voltage contacts could be separately screened.

Figures 5 and 6 show actual photomicrographs of the electrode patterns.

Measurements are performed as follows: A constant current source is connected between the large squares. The potential of the contact lines is probed by connecting one of the current electrodes on the Low side of a digital voltmeter with good resolution $10.1 \mathrm{mV}$ or better). The HIGH side of the voltmeter is then used to measure the potential on each line electrode. The potential measurements $\mathrm{V}(\mathrm{x})$ are then plotted as the ordinate against the dimensionless abscissa $x$. The transfer length is obtained by extrapolating the straight portion of $V(x)$ beyond $x=0$ to $V(x)=0$. Physically, the transfer length is the distance that the current must flow under the contact before $0.632 I$ is transferred to the contact. The resistance $\dot{R}_{q}$ can be calculated from

$$
R_{a}=\frac{\Delta V(x)}{I} \frac{Z}{L}
$$




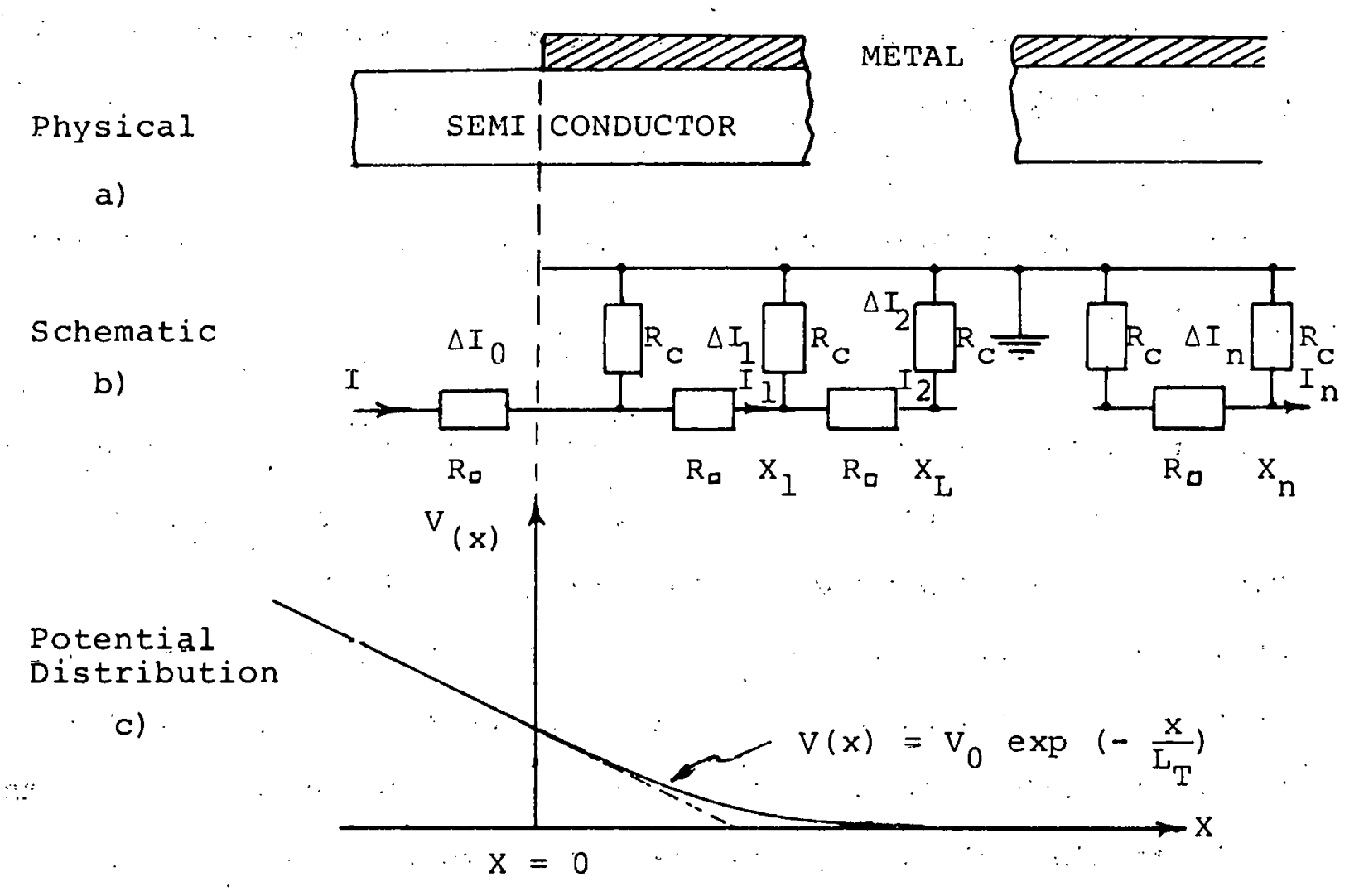

Fig: 3. Metal Semiconductor Contact. 


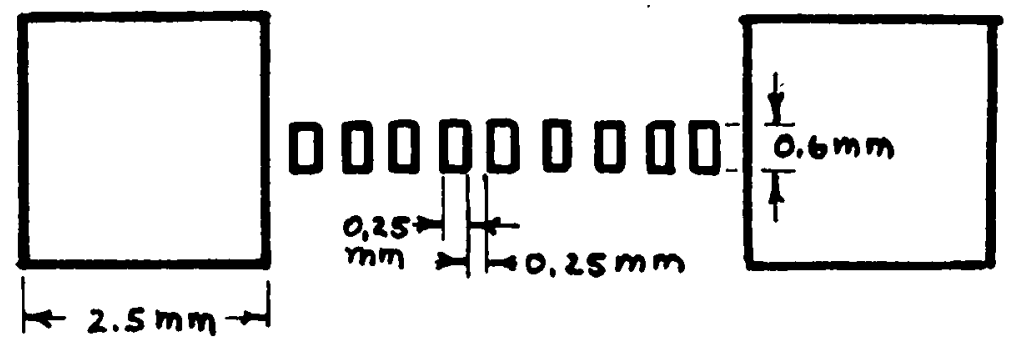

Figure 4. Masks for Contact Resistance Measurement

Page 10 


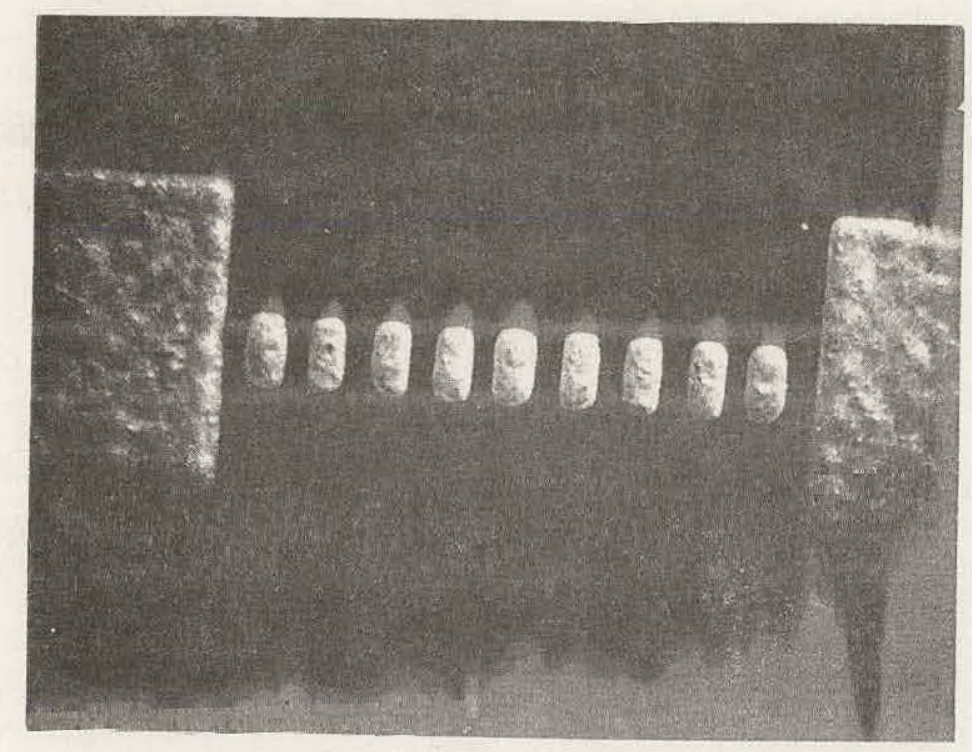

Fig. 5. S058 screened contact pattern for contact resistance measurement on polished silicon wafer prior to firing (Optical microscope magnification 13X).

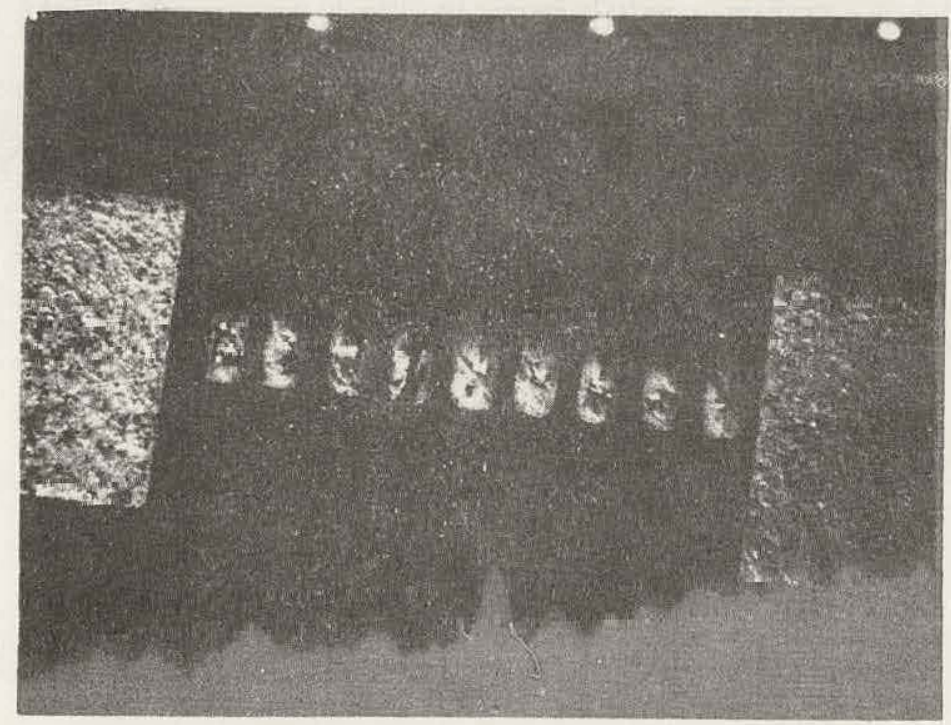

Fig. 6. S057 fired at $600^{\circ} \mathrm{C}$ in air screened on lapped silicon wafer. Scratches on contact pattern indicate probing from previous measurement. 


$$
\begin{aligned}
& \text { where } \begin{aligned}
\Delta V= & \text { the voltage drop along } \\
& \text { in Volts }
\end{aligned} \\
& L \equiv \text { length (in } \mathrm{cm} \text { ) of portion } \\
& \text { of the array carrying } \\
& I \equiv \text { current in amps } \\
& \mathrm{Z} / \mathrm{L} \equiv \text { number of squares in } \\
& \text { interval L (dimension- } \\
& \text { less) }
\end{aligned}
$$

The contact resistance $R_{C}\left(\right.$ in $\left.\Omega \mathrm{cm}^{2}\right)$ is obtained from the relation $R_{C}=L_{T}{ }^{2} R_{\square}$.

Initial measurements were plotted to gain familiarity with the method. The best straight line was drawn through the voltage points and the intercept on the $\mathrm{x}$ axis gave the transfer length $\mathrm{L}_{\mathrm{T}}$. Subsequently, a program was used to obtain the equation of the line using a regression coefficient to provide a measure of the degree of fit ( $K=1$ is the best obtainable). Data and plots for 5057 fired at $550^{\circ} \mathrm{C}$ and $600^{\circ} \mathrm{C}$ in nitrogen are given in the appendix. Results for S057, S058, and S059 have given values of contact resistance from the mid $10^{-4} \Omega \mathrm{cm}^{2}$ to $\mathrm{mid} 10^{-3} \Omega \mathrm{cm}^{2}$. 


\subsection{METAL SYSTEMS CONSIDERATIONS \\ 4.1 FABRICATION OF GERMANIUM-ANTIMONY EUTECTIC POWDER}

Initial attempts to produce eutectic alloys in a nitrogen atmosphere with germanium (Ge) and aluminum (Al) as well as antimony (Sb) powders respectively, were considered unsuccessful because of excessive oxidation. The attempt was repeated using a tube furnace with a hydrogen atmosphere continuously flowing past the sample (courtesy Applied Solar Energy Corp.). The constituents were weighed ( $11 \% \mathrm{Ge}$ in $\mathrm{Sb})$, mixed and packed in a Pyrex ${ }^{\mathrm{R}}$ beaker. The beaker was inserted through a flame curtain into the quartz tube of the furnace and placed in a relatively cool position. The beaker remained for five minutes in the warm hydrogen stream ( $0.5 \frac{\text { liter }}{\text { min }}$ ) to allow purging the powder of a major portion of the entrapped air. Then the beaker was pulled into the center nf the Iurnace which had equilibrated at $624^{\circ} \mathrm{C}$ and allowed to remain for 15 minutes. After insertion, the powder separated into two equal portions (vertically), with a gas space in between. After two minutes in the hot zone the gas space collapsed and densification was observed. After melting was visible, the process went to completion in two minutes. A black powder dross was found on top of the metal button. The dross was removed and the metal was found to be quite brittle and could easily be reduced to a coarse grained powder with a hammer in a plastic bag. Further reduction in grain size was easily accomplished with a mortar and pestle. 
A solar cell experiment was done at the premises of Applied Solar Energy Corporation with the cooperation of P.A. Iles and others. Since the antimony fraction of the inks is highly susceptible to oxidation, the ink firing operations were done in flowing hydrogen (10 minutes). Upon insertion of the cells it was noted that the screened back contact sometimes lifted and curled up. Similarly the adhesion of the front contact was very poor in some cases, coming off while maintaining identity as grid lines or collector busses.

In a previous experiment a similar result was observed with an antimony containing ink (S034). The explanation at that time was thought to be the formation of a eutectic liquid (antimonysilver), melting at $485^{\circ} \mathrm{C}$ with $44 \%$ antimony. It was felt that the surface tension resulting from the additional liquid might overcome the adhesion to the silicon. The quantities involved make this hypothesis weak:

$$
\begin{aligned}
& \mathrm{Pb} \text { (Iiquid) } 5 \text { wt\% } \\
& (\mathrm{Sb} 0.1 \text { wt\% }+ \text { Ag } 0.1 \text { wt\%) (1iquid). }
\end{aligned}
$$

The additional amount of liquid can only be

$$
\frac{0.2 \mathrm{Ag}(+\mathrm{Sb})}{5.0 \mathrm{~Pb}}=.04 \text { or } 4 \mathrm{wt} \% \text { of the liquid. }
$$

The other ink utilized S059, contained Ge-Al eutectic and gallium chloride. Print fragments from the lifted electrodes were mounted 
and subjected to SEM examination. The results can be seen in the following pages. Figure 7 shows 5034 (58 Pb, $28 \mathrm{AgF}, 938 \mathrm{Ag}$, $0.1 \% \mathrm{Sb})$ at low magnification (200X). Figures 8,9 and 10 show increasing magnification, and at least the appearance seems to support the above hypothesis showing a continuous sheet of metal with highly occasional pores. This is quite different from the lacy matrix of sintered silver grains which are typical for these electrodes. At the last two magnifications the rod shaped structures can be seen which were previously identified as the precipitated lead ${ }^{5}$.

The appearance of the other electrodes is different and Figures 11 and 12 show portions from a print of 5063 (masterpaste with germanium-antimony eutectic and probably oxides) at increasing magnifications, $510 \mathrm{x}$ and $5100 \mathrm{x}$ respectively. The color difference could be due to oxide mixtures, bearing in mind that the imaging current of the SEM derives from secondary electron yield rate, which could, in turn, be caused by charging effects. In any case the 'solid sheet' nature of the previous pictures is absent and we have a typical sintered structure. The occasional horizontal raster effect seen in Figure 12 is an artifact of the instrumentation.

The electronmicrographs from S059 (masterpaste + 5\% Ge-Al eutectic $+1 \%$ gallium chloride) appear to be a combination of the previous pictures. Figures 13, 14 and 15 show magnification of $1000 \mathrm{x}$, $5000 \mathrm{X}$ and $10,000 \mathrm{x}$ of the subject peeled electrode. The discoloration 


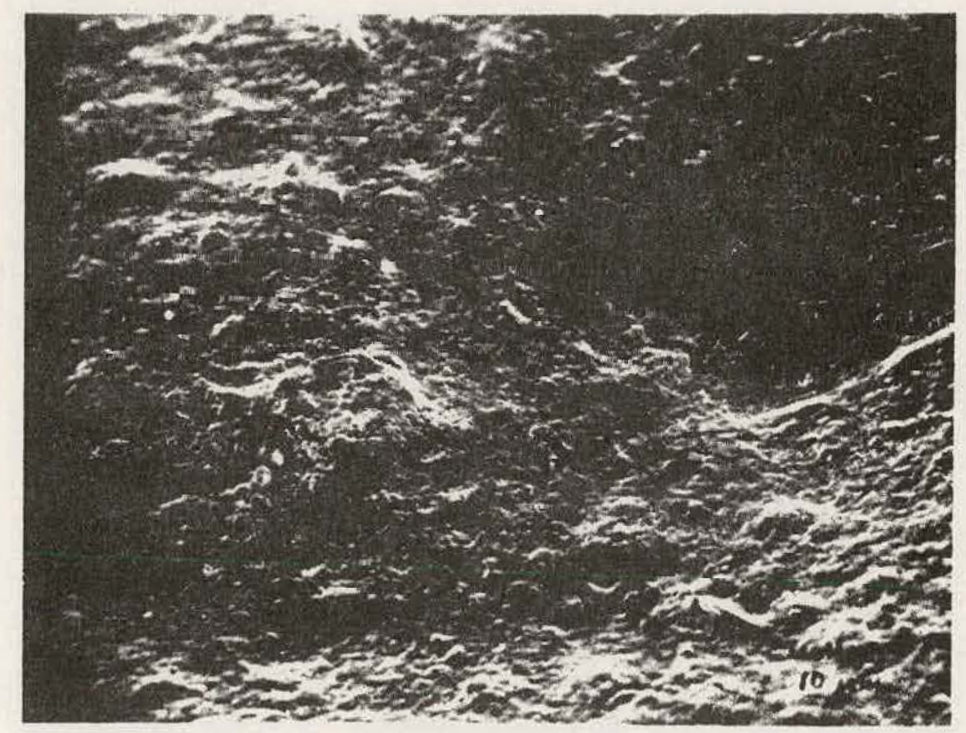

Fig. 7. Photomicrograph of peeled electrode print S034 fired in hydrogen at $650^{\circ} \mathrm{C}$ taken on Cambridge SEM at magnification $200 \mathrm{X}$.

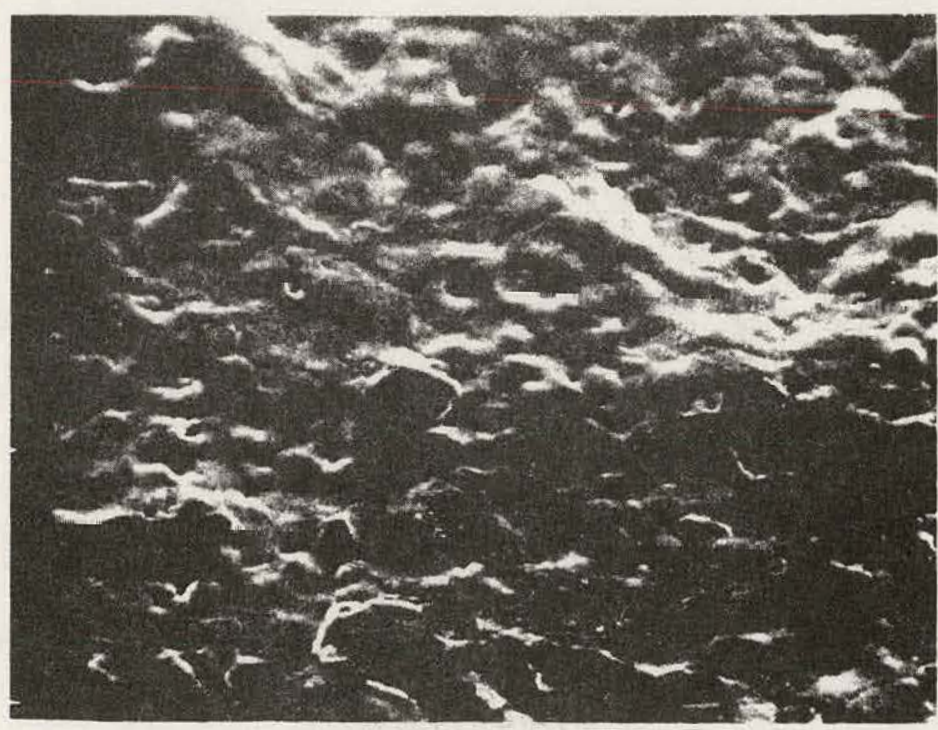

Fig. 8. Same as Fig. 7 at magnification $1000 x$. 


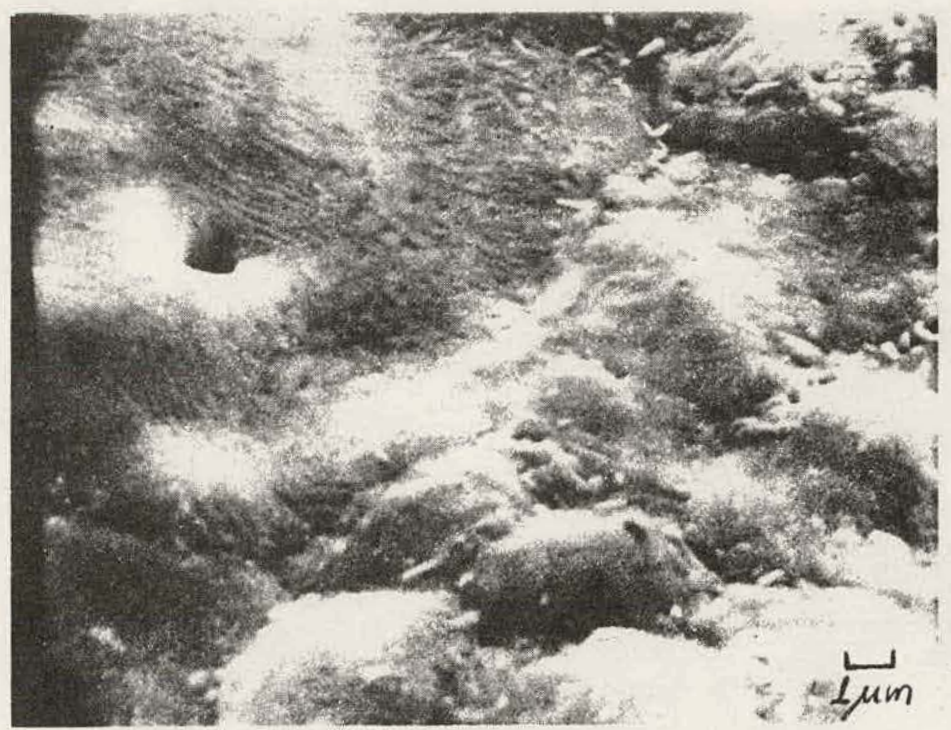

Fig. 9. Same as Fig. 7 at magnification $5000 x$.

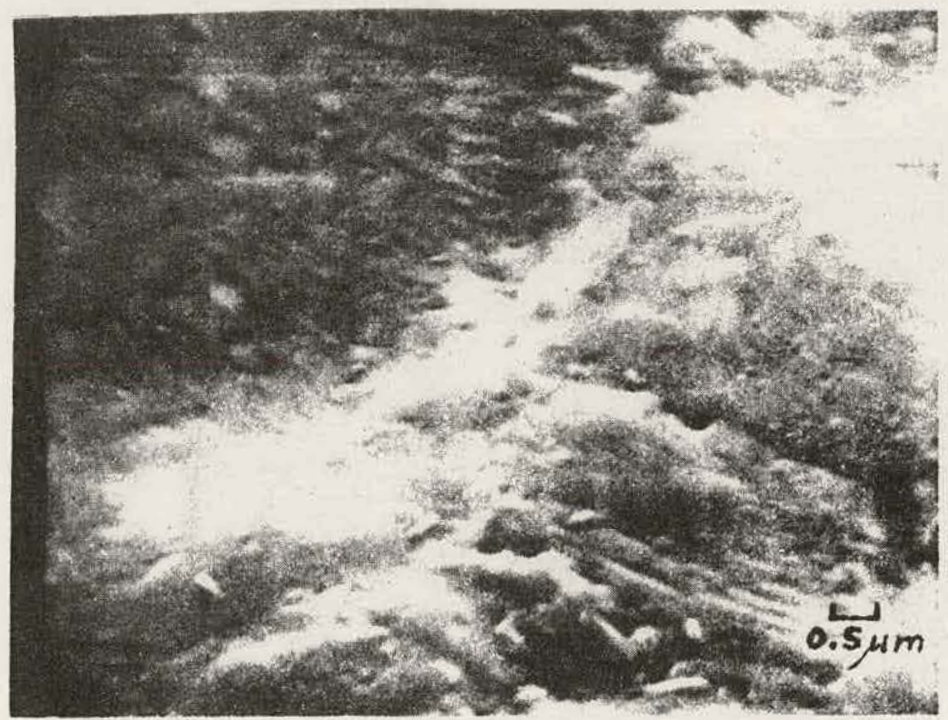

Fig. 10. Same as Fig. 7 at magnification 10,000x. 
effect is the same as in the case of $\mathrm{S} 063$, supporting the contention of oxide mixture, but the electrode appears oversintered with few voids. At this point we do not have an adequate explanation of the observed phenomenon.

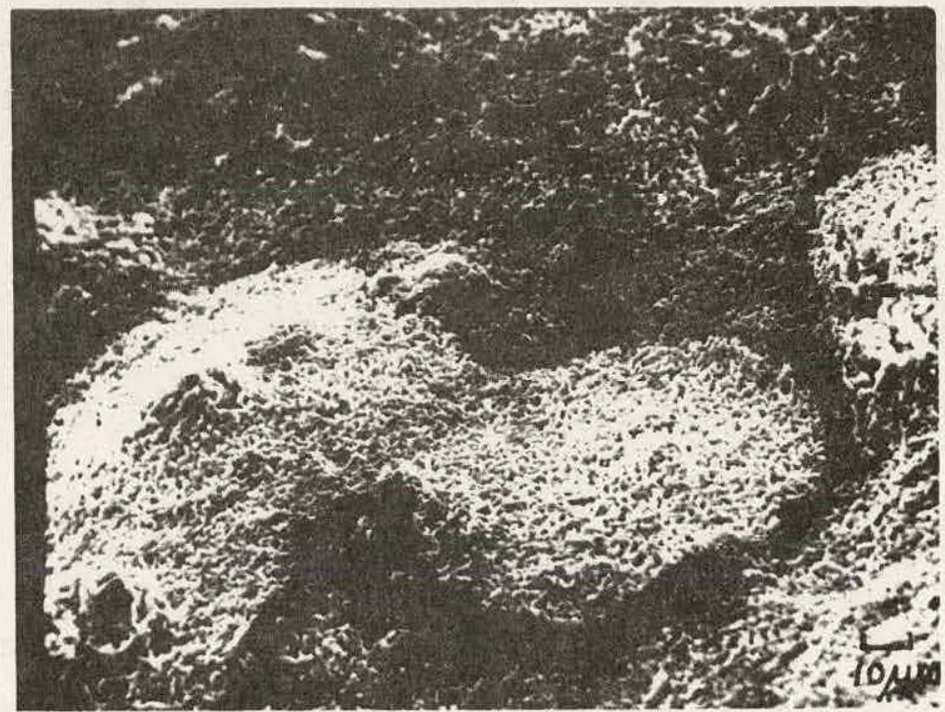

Fig. 11. Photomicrographs of peeled electrode print S063 fired in hydrogen at $650^{\circ} \mathrm{C}$ taken on Cambridge SEM at magnification 5l0X.

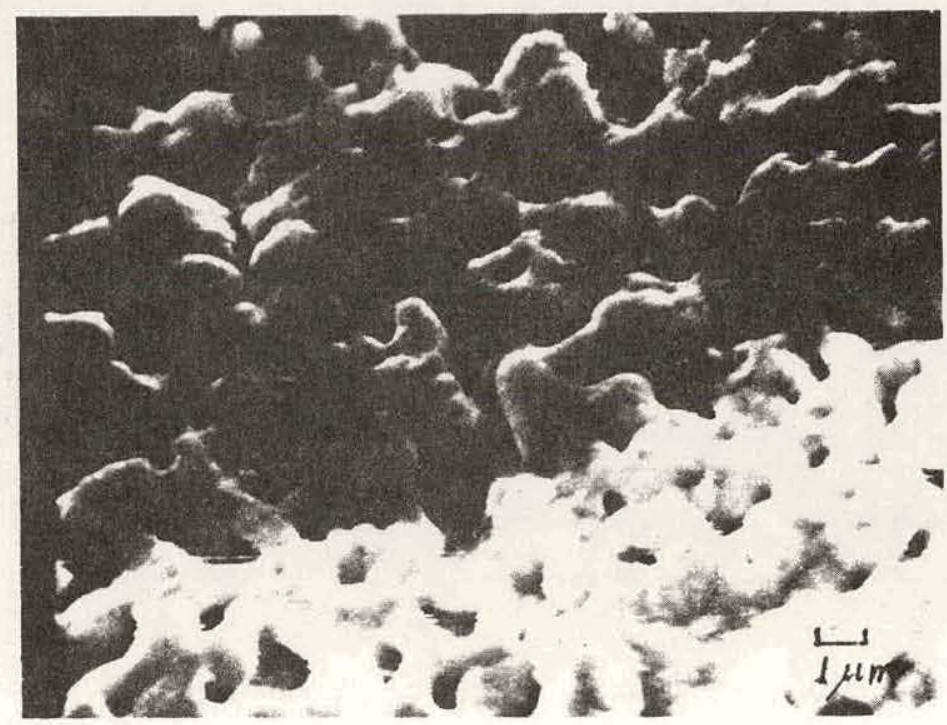

Fig. 12. Same as Fig. 11 at magnification 5,100x. 


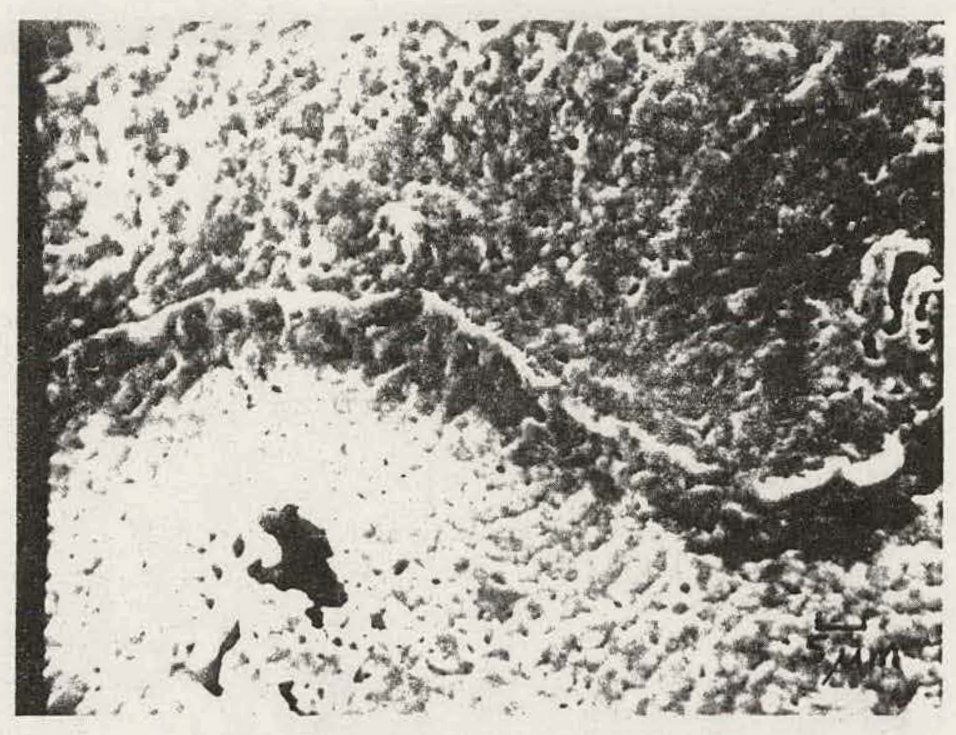

Fig. 13. Photomicrograph of peeled electrode of print 5059 fired in hydrogen at $650^{\circ} \mathrm{C}$ taken on Cambridge SEM at magnification 1000X.

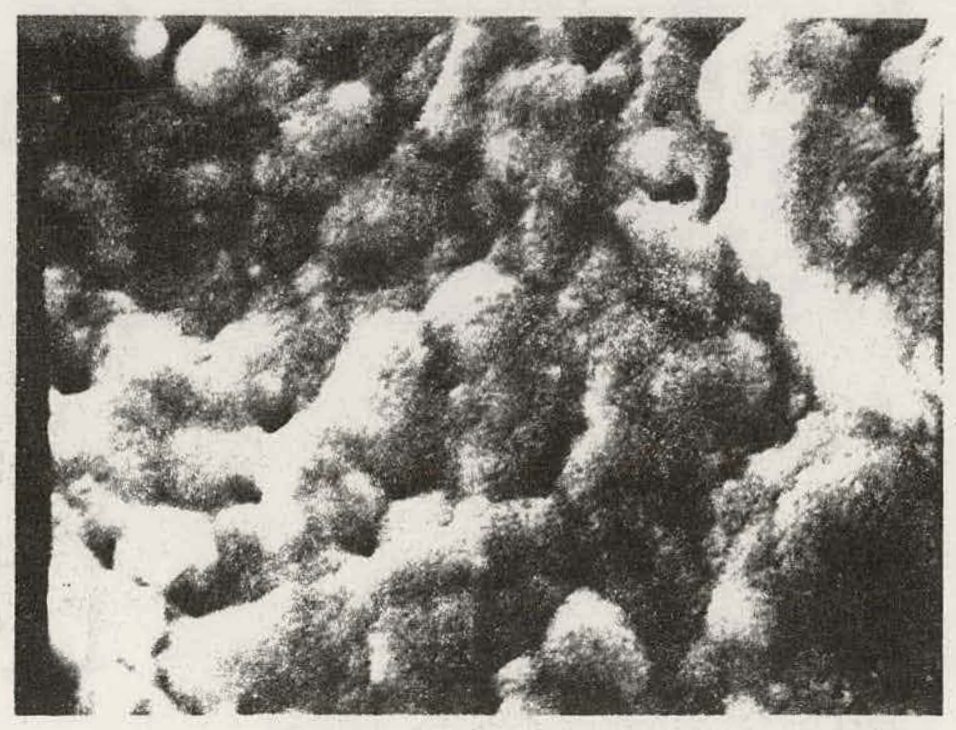

Fig. 14. Same as Fig. 13 with magnification 5,000x. 


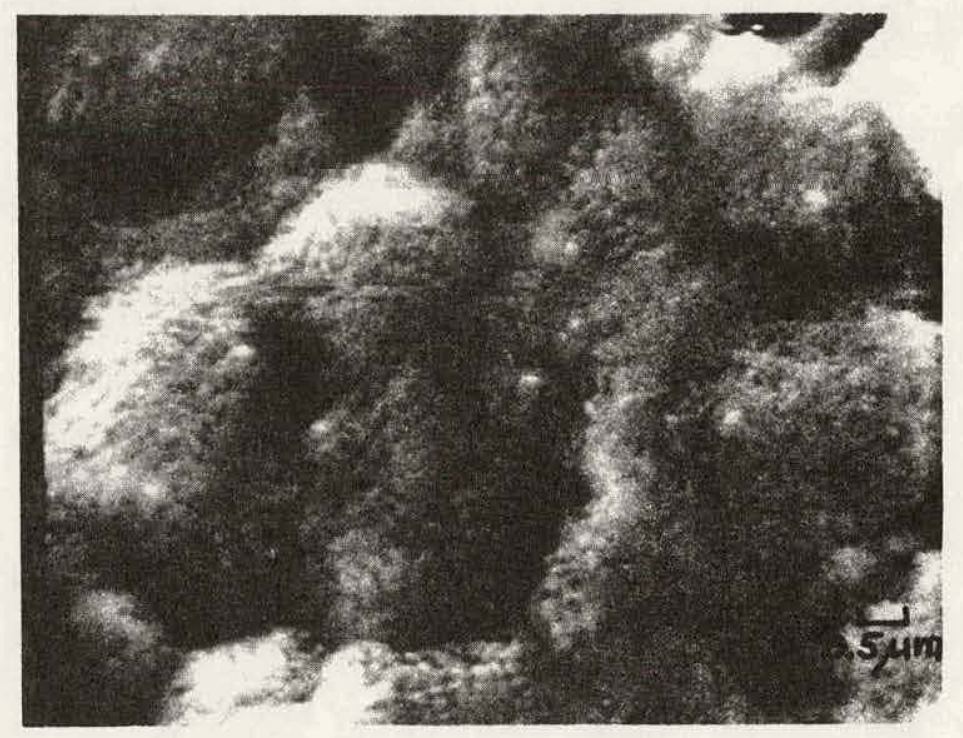

Fig. 15. Same as Fig. 13 with magnification 10,000X. 
Cells tested consisted of four controls with titanium-palladiumsilver ( $\mathrm{T} i-\mathrm{Pd}-\mathrm{Ag})$ evaporated front and back contacts sintered at $600^{\circ} \mathrm{C}$ and $650^{\circ} \mathrm{C}$ respectively, three textured front surface cells and three cells with regular polished front surfaces. All of the surviving cells had $\mathrm{Ti}-\mathrm{Pd}-\mathrm{Ag}$ evaporated back contacts and were fired at $600^{\circ} \mathrm{C}$ or $650^{\circ} \mathrm{C}$ in hydrogen. The original curve traces are reproduced in the Appendix 2.

Of the four control cells, two showed sharp decreases in open circuit voltage, which was an even more serious problem in the experimental celis. This might be due to a junction processing problem resulting in spotty low shunt resistance. The restricted number of cells is due to a cell availability problem at the time lle experiment was run.

All the experimental cells had poor open circuit voltages. The cells fired at $650^{\circ} \mathrm{C}$ showed open circuit voltages about half of those fired at $600^{\circ} \mathrm{C}$, indicating more severe shunting at the higher temperature. Likewise, the ink containing the hydrogenreacted Ge-Sb eutectic gave much higher open circuit voltage. than the nitrogen-air reacted material (see Table 1). 
Five percent of this material was combined with masterpaste s032 (93\% Ag - 5\% $\mathrm{Pb}$ and $2 \% \mathrm{AgF})$ to result in 5064 for use on the phosphorous diffused layer. Other inks tried in this experiment were 5063 (composition similar to 5064 but with the eutectic alloyed in air) and s059, a $P$ type ink with a 5\% germaniumaluminum eutectic and 18 gallium chloride. The Ge-Al eutectic is also suspect since it was reacted in a nitrogen atmosphere containing unknown amounts of room air.

Table 1. Electrical Results

\begin{tabular}{|c|c|c|c|c|c|c|}
\hline \multirow[t]{2}{*}{ PASTES } & \multicolumn{6}{|c|}{ TEMPERATURES } \\
\hline & Isc & $\begin{array}{l}600 \\
(\mathrm{~A})\end{array}$ & Voc (V) & Isc & $\begin{array}{l}65 \\
\left(A_{1}\right)\end{array}$ & C $\operatorname{Voc}(\mathrm{V})$ \\
\hline s063 & -- & & -- & .3 & 3 & .06 \\
\hline S064 &. .41 & & $: 26$ & .3 & & .13 \\
\hline Controls & .58 & & .56 & .4 & 49 & .52 \\
\hline Controls & .58 & . & .27 &. .4 & 47 & $i^{12}$ \\
\hline
\end{tabular}


The silver-lead and silver-tin systems have been investigated previously ${ }^{6}$ with good results in the case of silver-lead, leading to low temperature liquid phase sintering. In view of the above it is useful to review the phase diagram ${ }^{7}$ of this system, Fig. 16, and plot the solubility curve, Fig. 17.

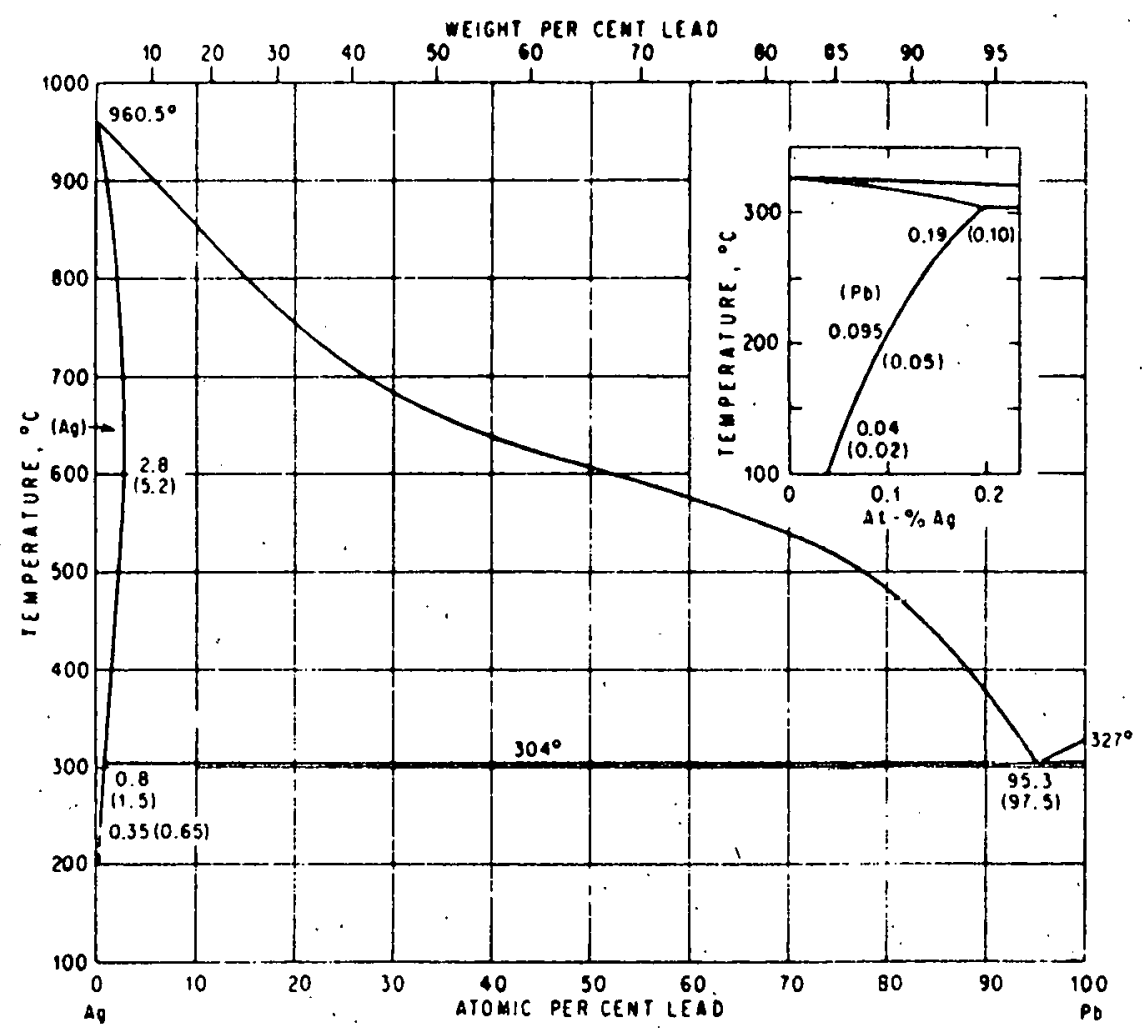

Fig. 16. Equilibrium Phase Diagram of Silver-Lead System. 
The solubility of silver in the lead rich melt can be obtained from the locus of the intersections of isotherms with the liquidus curve.

\section{SILVER DISSOLVED}

IN LIQUID LEAD

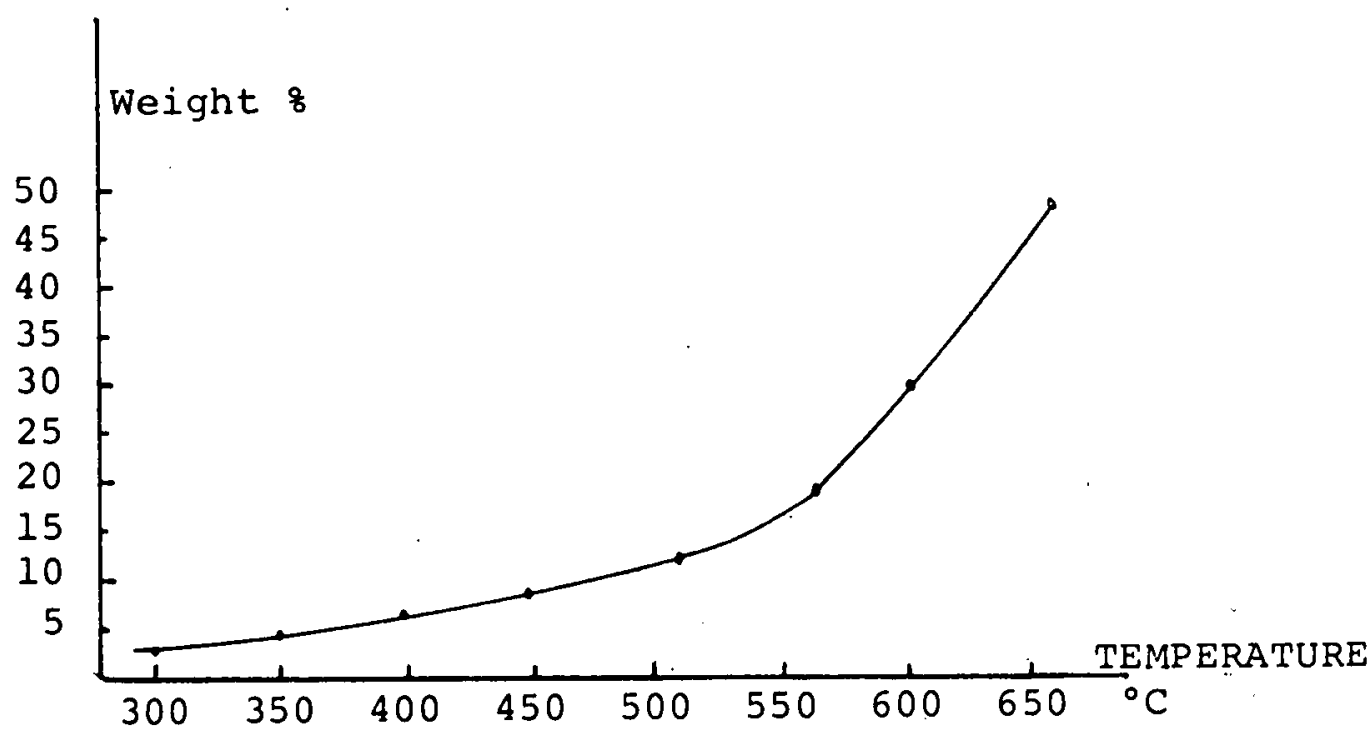

Fig. 17. Solubility Curve of silver-Lead system.

The solubility of silver in liquid lead is quite large.

Figure 18 shows the phase diagram of the nickel tin system and Fig. 19 the corresponding solubility plot. It can be seen that the solubility of silver in lead at $400^{\circ} \mathrm{C}$ is almost exactiy one order of magnitude higher than the nickel solubility in tin at $400^{\circ} \mathrm{C}$. On the basis of solubility only, the nickel tin system does not have a high probability of success. 


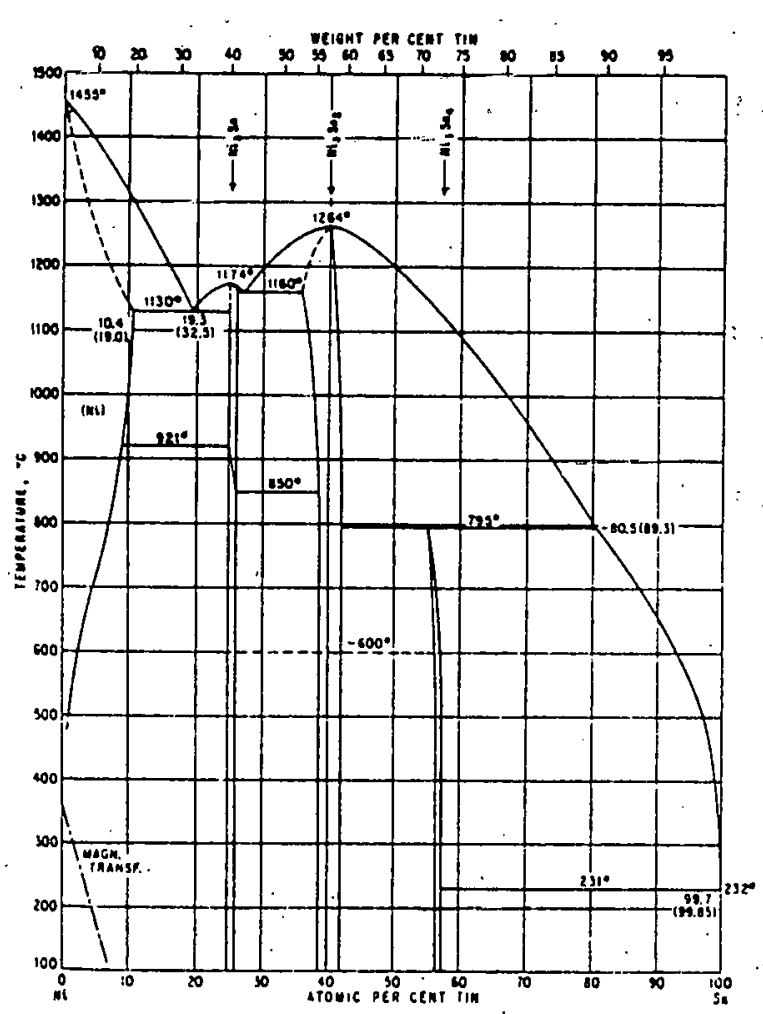

Fig. 18. Equilibrium Phase Diagram of Nickel-Tin System.

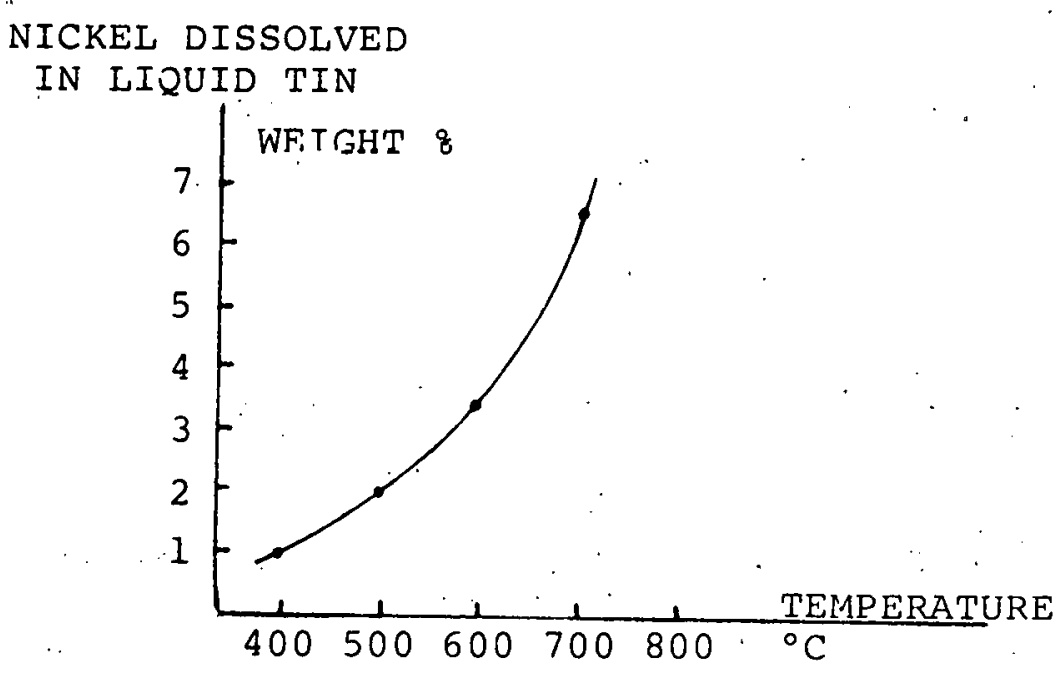

Fig. 19. Solubility Curve of Nickel-Tin System. ... 
The phase diagram of nickel-lead is shown in Figure 20. It can be seen that a considerable miscibility gap exists. The solubility of nickel in the lead melt is given in Fig. 21 and is relatively low up to quite high temperatures.

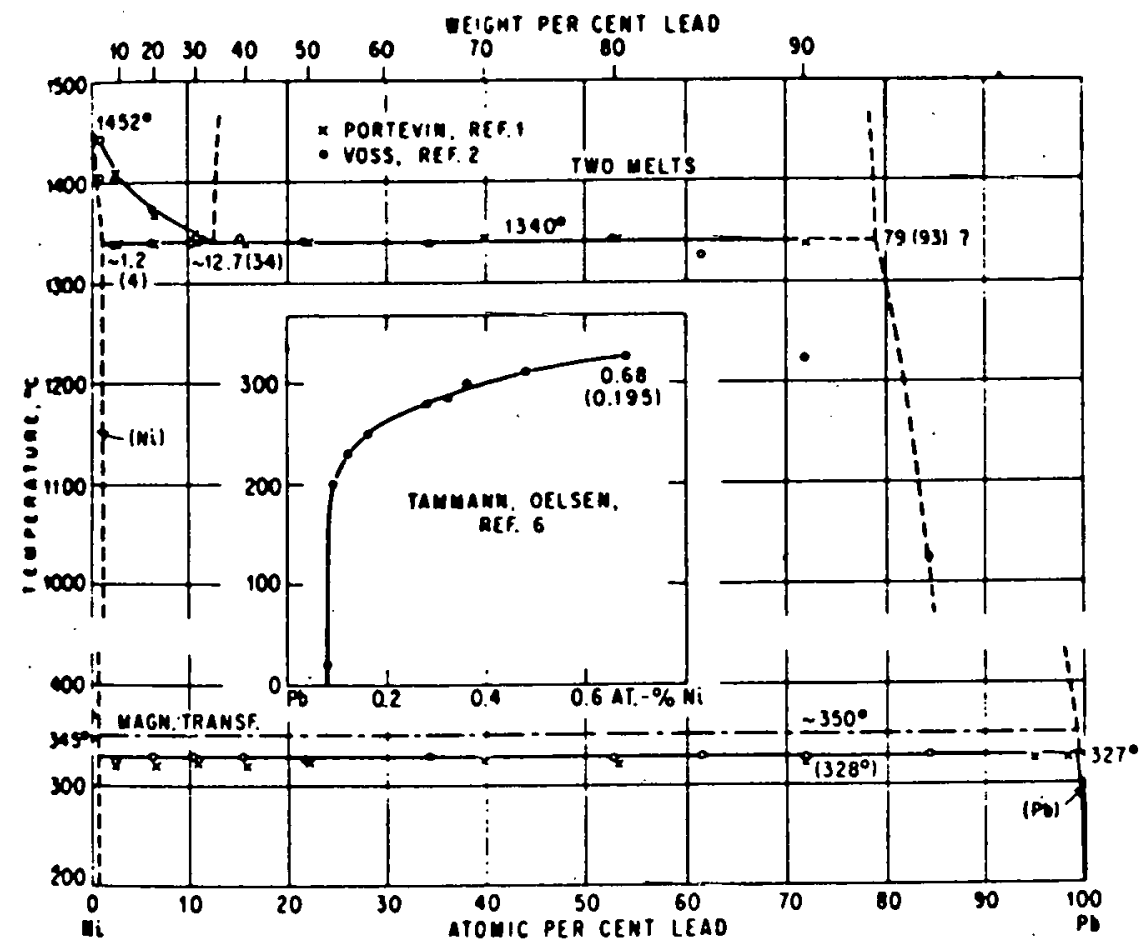

Fig. 20. Equilibrium Phase Diagram of Nickel-Lead system. 
NICKEL DISSOLVED

IN LIQUID LEAD

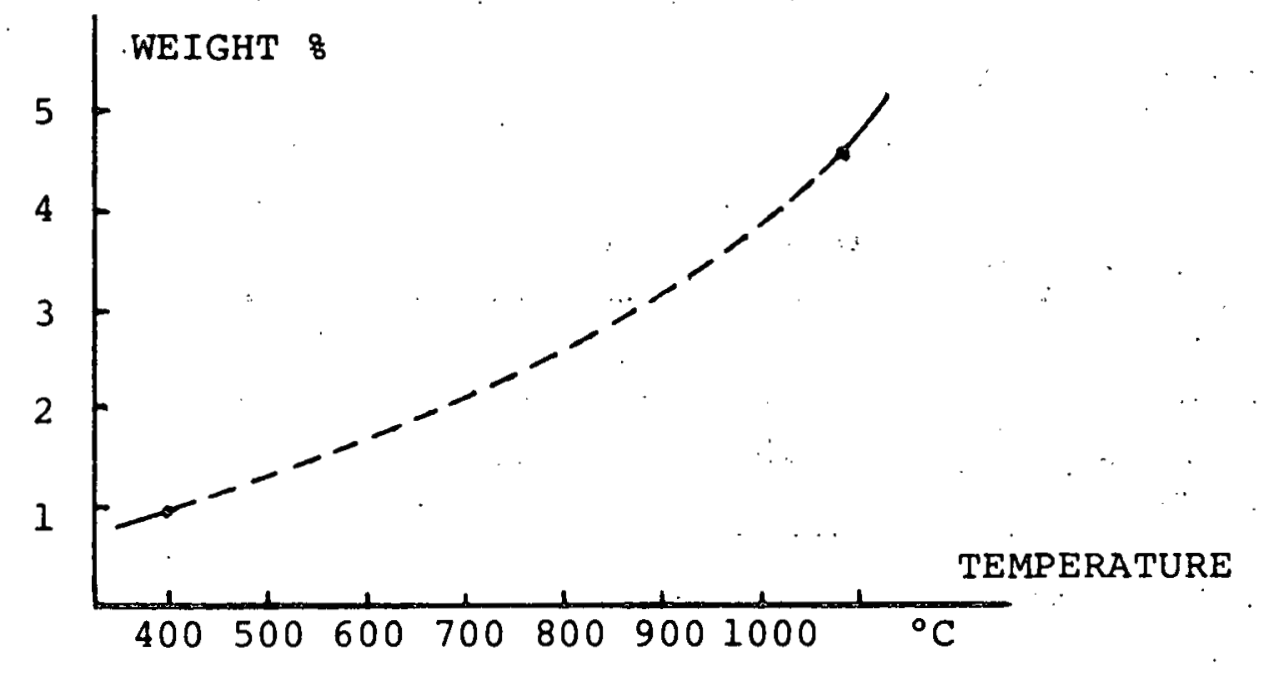

Fig. 21. Solubility Curve of Nickel-Lead System.

The dashed portion of the curve is estimated since no data was found in the literature.

A number of nickel systems have more favorable solubility factors, however they are often associated with metals having fairly high vapor pressures. Some of these are nickel-antimony, nickel-zinc and nickel bismuth. The phase diagrams of these systems are reproduced in the appendix 9. 
A phase diagram of nickel-silicon is shown in Figure 22 .

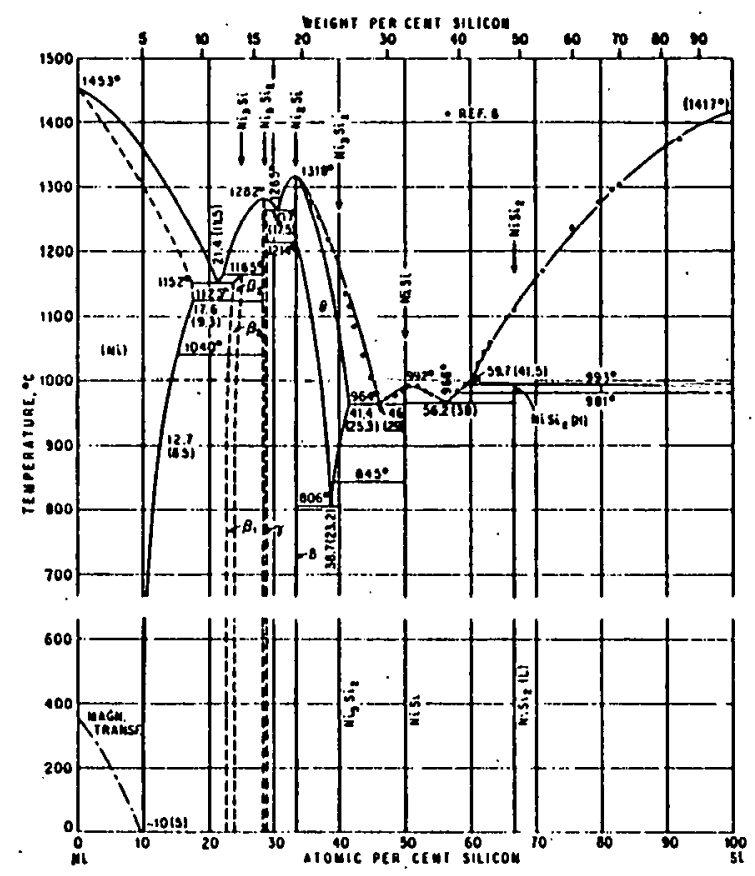

Figure 22. The nickel silicon system

Aside from its complexity, it shows the temperature of the lowest melting eutectics between silicon and nickel, which should not be approached in any firing cycles. While.this is an absolute temperature limit, melting may occur at lower temperatures depending upon other additives to the paste composition such as aluminum and germanium. 
The copper systems were also examined. The copper-lead phase diagram is given in Figure 23.

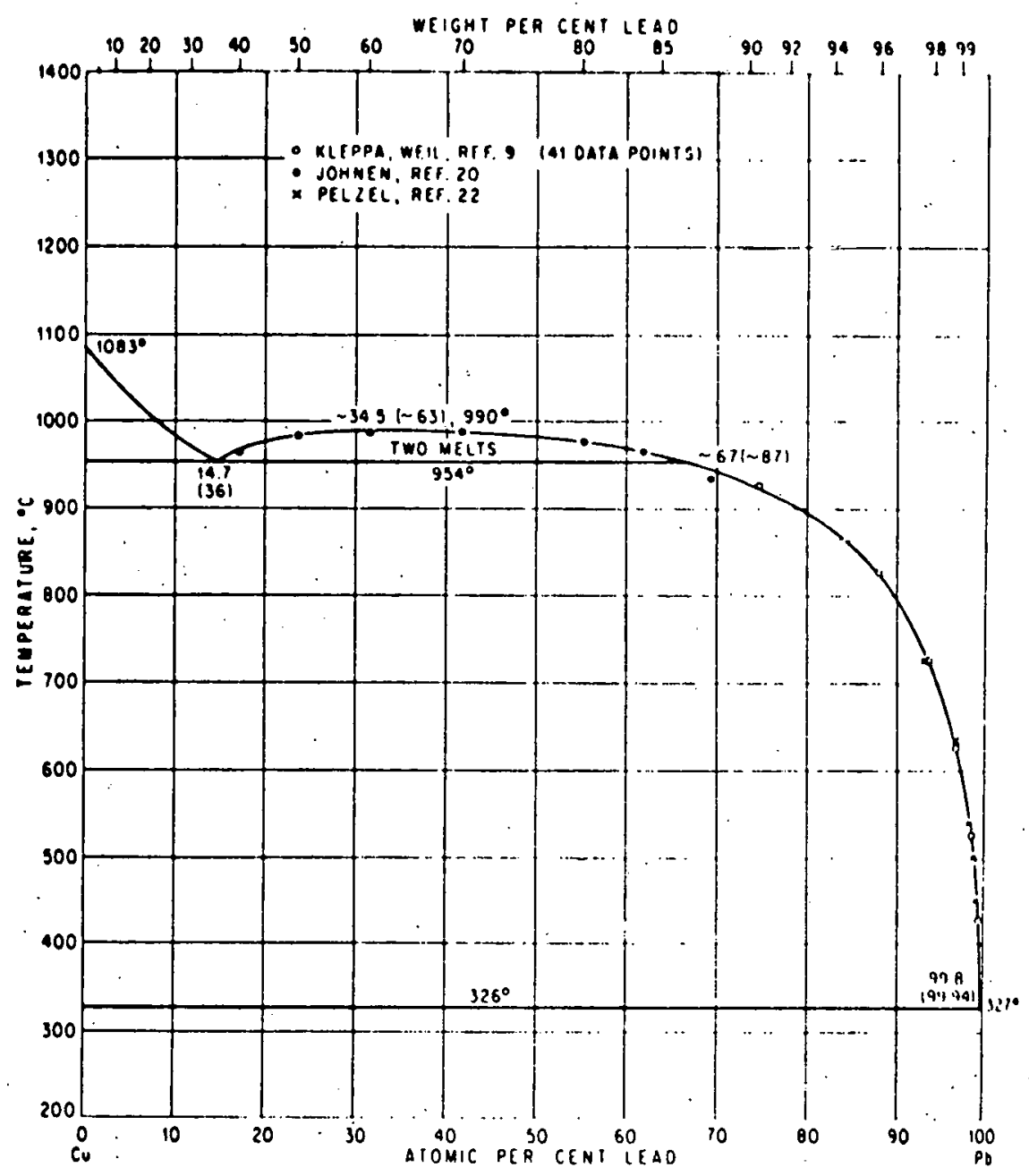

Figure 23. The equilibrium phase diagram for the copper-lead system. 
The copper solubility curve in liquid lead is shown in Figure 24. Again the solubility is quite low until considerable temperatures are reached.

COPPER DISSOLVED

IN LIQUID LEAD

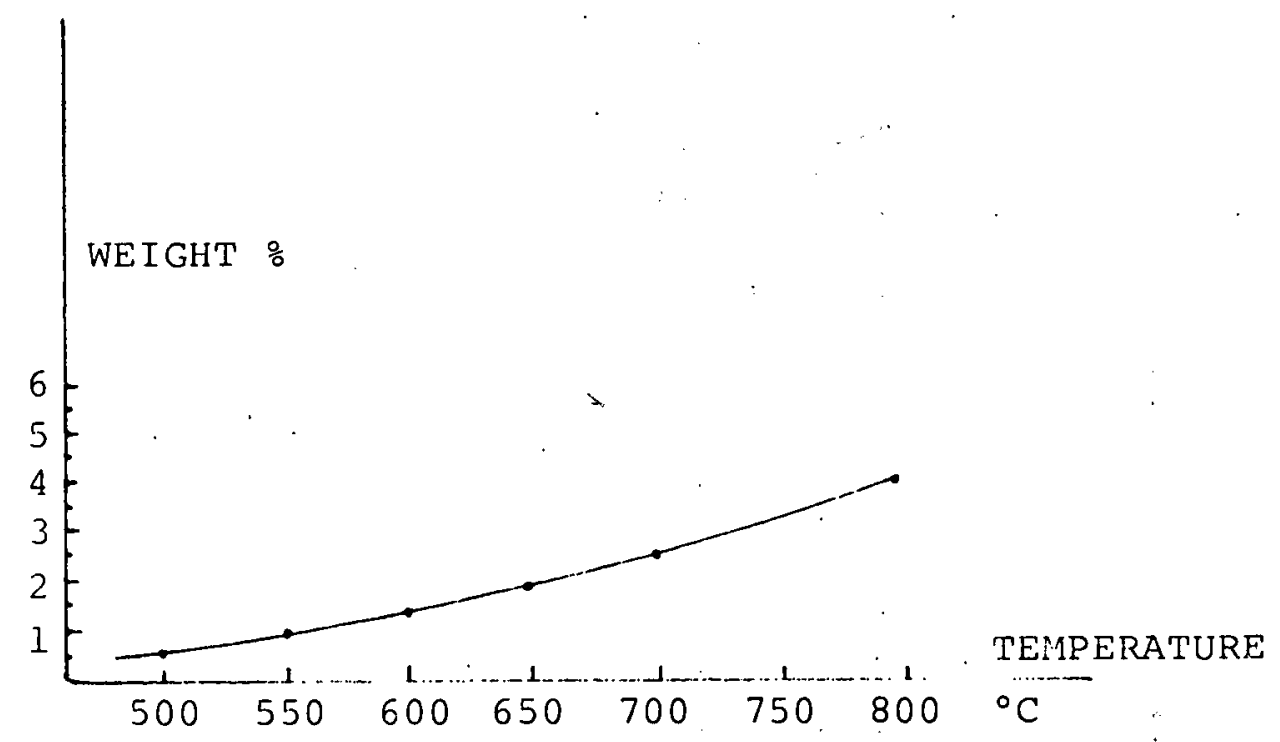

Figure 24. Copper solubility in a lead melt

Other systems again showing a higher solubility of copper can be found in the appendix. The copper aluminum system may be singled out as an interesting one, as it combines a relatively high melt solubility with a metal commonly used as doping metal in p-type silicon. However the combination of the metals tends to have severe corrosion problems in wet atmospheres. 
In Figure 25 the phase diagram of silicon-copper is given to establish the upper temperature limit of thermal processes involving that system: As can be seen the absolute temperature limit of heating the copper silicon system is $802^{\circ} \mathrm{C}$, however the same caveat applies as was previously mentioned with regard to potential temperature depressant additives.

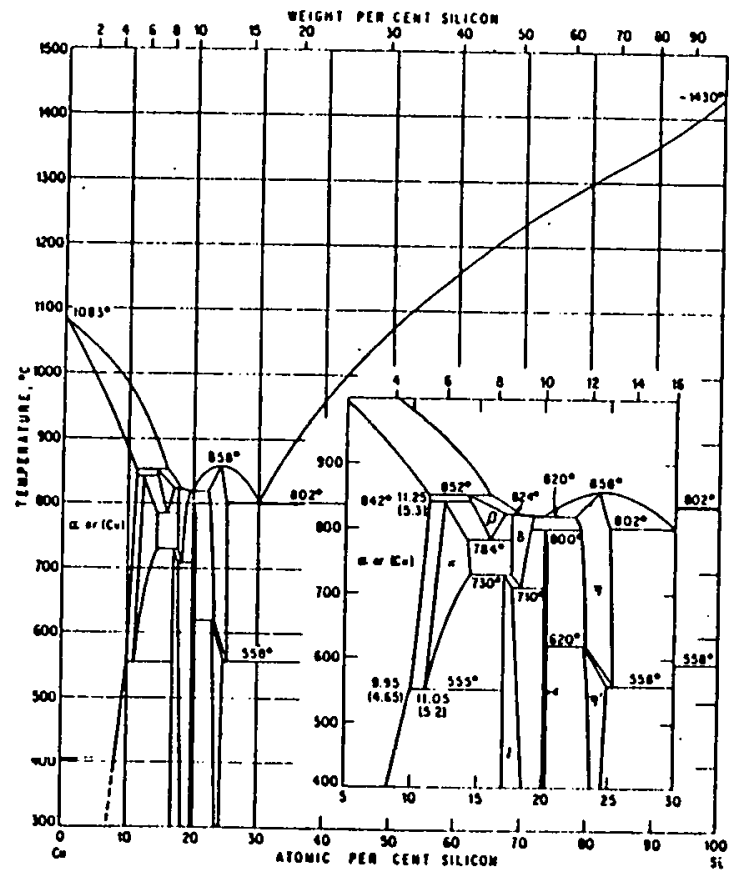

Figure 25. The Copper Silicon System

In the use of copper in contact with silicon further comments are appropriate. Copper was suspected early in semiconductor technology as the major recombination center in germanium and silicon (Collins et $\mathrm{al}^{8}$ ). Work by the present author in 1957 indicated that silicon with a high initial copper concentration introduced at high temperatures, but undergoing slow cooling suffered no minority carrier lifetime degradation ${ }^{9}$. Nevertheless copper in silicon devices has remained suspect for a 
quarter century. A recent study of the severity of various impurities in silicon material ${ }^{10}$ has corroborated the author's experience. Another degradation mechanism attributable to copper is its tendency to diffuse rapidly through the lattice and precipitate in clusters on defects or dislocations, leading to decoration of defects $\left(\right.$ Dash $\left.^{11}\right)$. Therefore a copper spike can be driven through the space charge region of a $p-n$ junction by allowing copper to diffuse and aggregate on an edge dislocation perpendicular to the wafer and junction. This can lead to severe junction shunting, particularly when an array of dislocations exists. Since copper is a particularly rapid diffuser, direct contact between silicon and copper should be avoided. The role of barrier metals is presently being investigated by several researchers. In any case, processing steps and structures must be carefully planned in the presence of copper metallization. 
Although the phase diagrams and solubility curves did not look: very favorable, it was decided to do experiments with nickel-lead and nickel-tin, copper-lead and copper-tin due to the immediate availability of materials, and the benign character of lead (chemical resistance, oxidation resistance). in our experience with the lead silver system and others.

Table 2 shows the constitution of all metal inks compounded during this period.

$$
\text { Table } 2 \text {. }
$$

All Metal Pastes Fabricated During Current Quarter

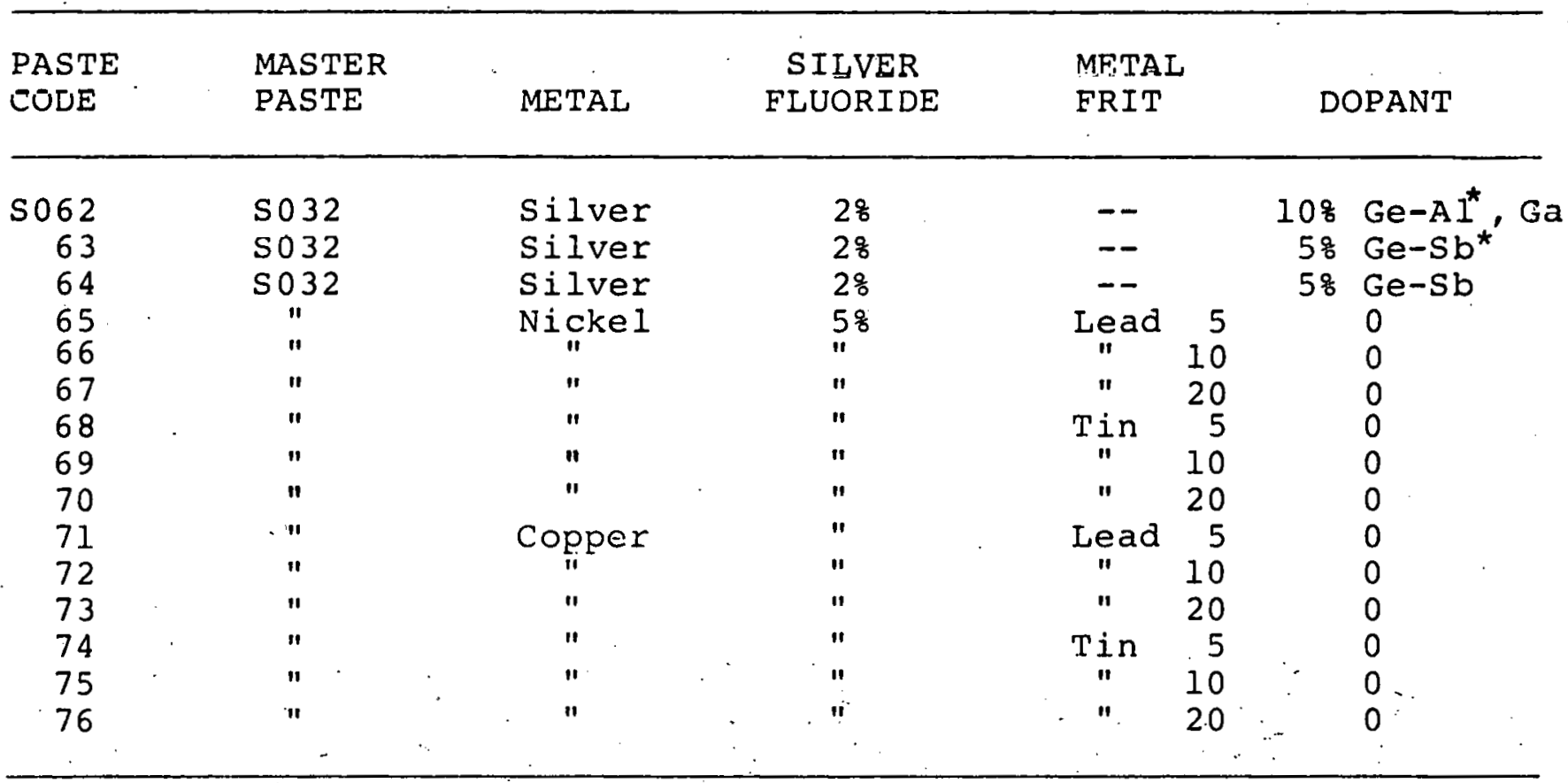

\section{eutectic not satisfactory.}

Firing of these inks awaits operational status of the tube furnace recently purchased and the gas handling system being installed. 
Masks were fabricated adapting the Shockley method for contact resistance measurement to thick film technology. A series of measurements were made on pastes with eutectic additives screened onto modest resistivity p-type silicon. Results were good, but must be viewed with caution until the measurements can be verified by independent means. Problems with measurement reproducibility were experienced and were due to the digital voltmeter.

Early pastes made with eutectic additions for doping purposes have been suspect due to the likelihood of oxidation of the powder constituents prior to eutectic alloying.

Hydrogen firing has produced adhesion problems, possibly relating to increased powder wetting, or interference with the etching action of the silver fluoride fluxing agent. In the case of basemetal inks the situation may change and the experimental evidence must be assessed at that time.

A detailed analysis of solubilities of copper and nickel in various liquid metals was made and compared with silver solubilities in the systems in which experience was acquired. Results of solar cell tests to date have been disappointing. This may be partially due to inadeguate eutectic powders:: 
In order to allow increased flexibility in experimentation a tube furnace was purchased. A gas-handling system, gases to allow use of reducing atmospheres, as well as clean inert atmospheres will be acquired at the facility of Bernd Ross Associates. 
The furnace and associated equipment will be installed and calibrated. Additional nickel and copper sources will be sought to establish a range of physical powder parameters.

Further eutectic and doping experiments will be done after the furnace installation is operational.

Pastes will be prepared from available stock of nickel and copper powder with tin and lead. Solar cell tests will be done with base metal inks doped with eutectic powders, assuming the metallurgical problems are surmountable. 


\subsection{PROGRESS ON PROGRAM PLAN}

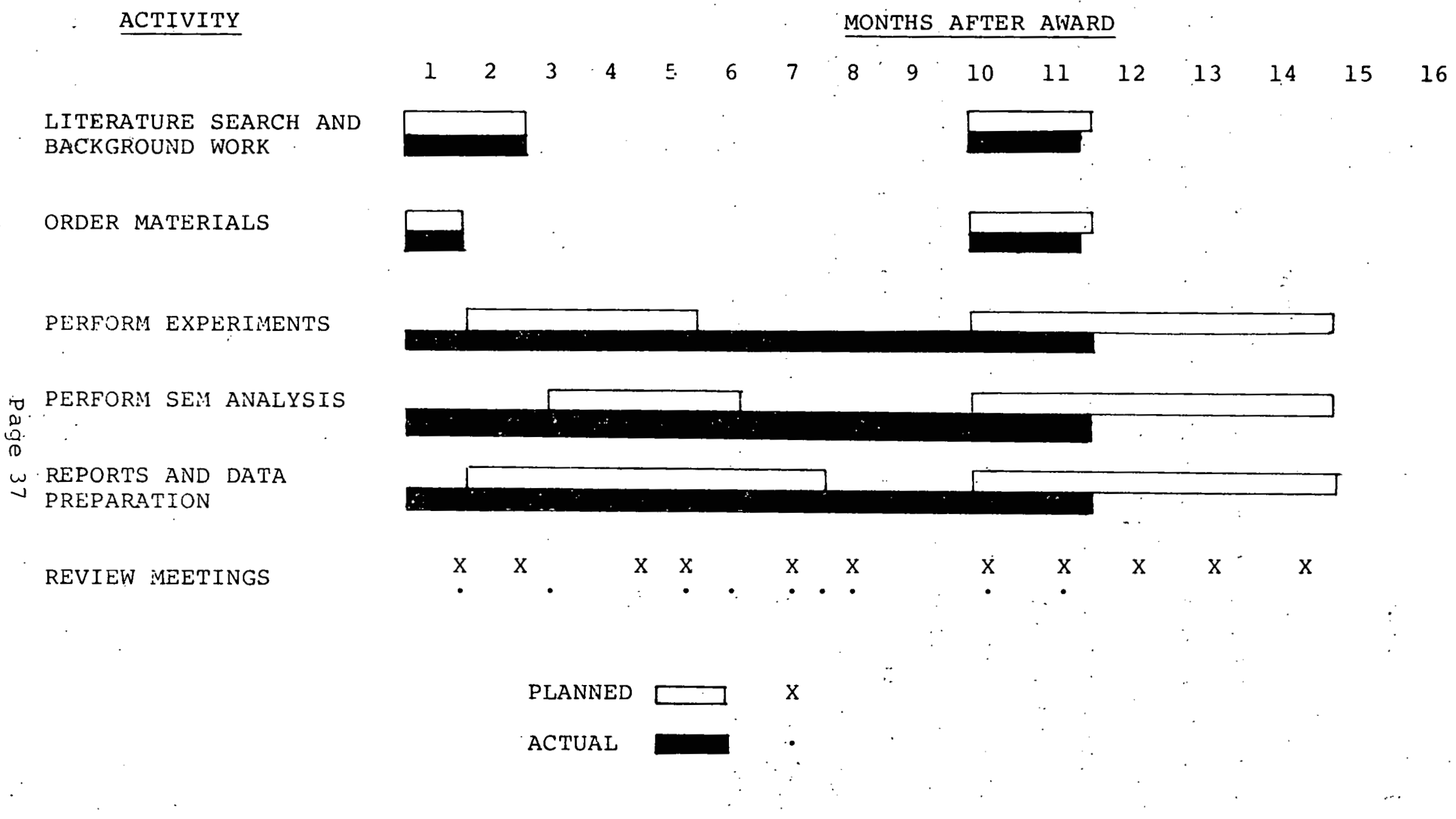




\subsection{PROGRESS ON PROGRAM PLANT (continued)}

PROGRAM ACTIVITY

PHASE I 1.0

PHASE II 2.0

1.1 Ohmic Contact Optimization

2.1

1.2 Contact Conductance

2.2

1.3 Pull Test

2.3

1.4 Temperature-Humidity Cycle

2.4

1.5 Solder Leach Resistance

2.5

1.6 Firing Temperature-Time optimization

2.6

1.7 Vehicle Percent Solids Optimization

2.7

1. 8 Reports and Documentation

1.9 Review Meetings
MONTHS AFTER AWARD

$\begin{array}{llllllll}1 & 2 & 3 & 4 & 5 & 6 & 7 & 8\end{array}$

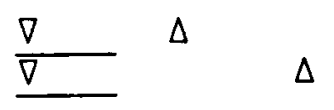

$\nabla \Delta$

$\nabla \Delta$

$\nabla \Delta$

$\nabla \Delta$

$\nabla \Delta$

$\nabla \Delta$

$\nabla \Delta$

$\nabla \Delta$

$\underline{\nabla} \Delta \nabla \Delta$

$\underline{\nabla \Delta}$

$\nabla \Delta$

$\nabla$

$\mathrm{X} \times \mathrm{X} \times \mathrm{X}$ 


\subsection{APPENDIX}

Page 39 
APPENDIX A.I

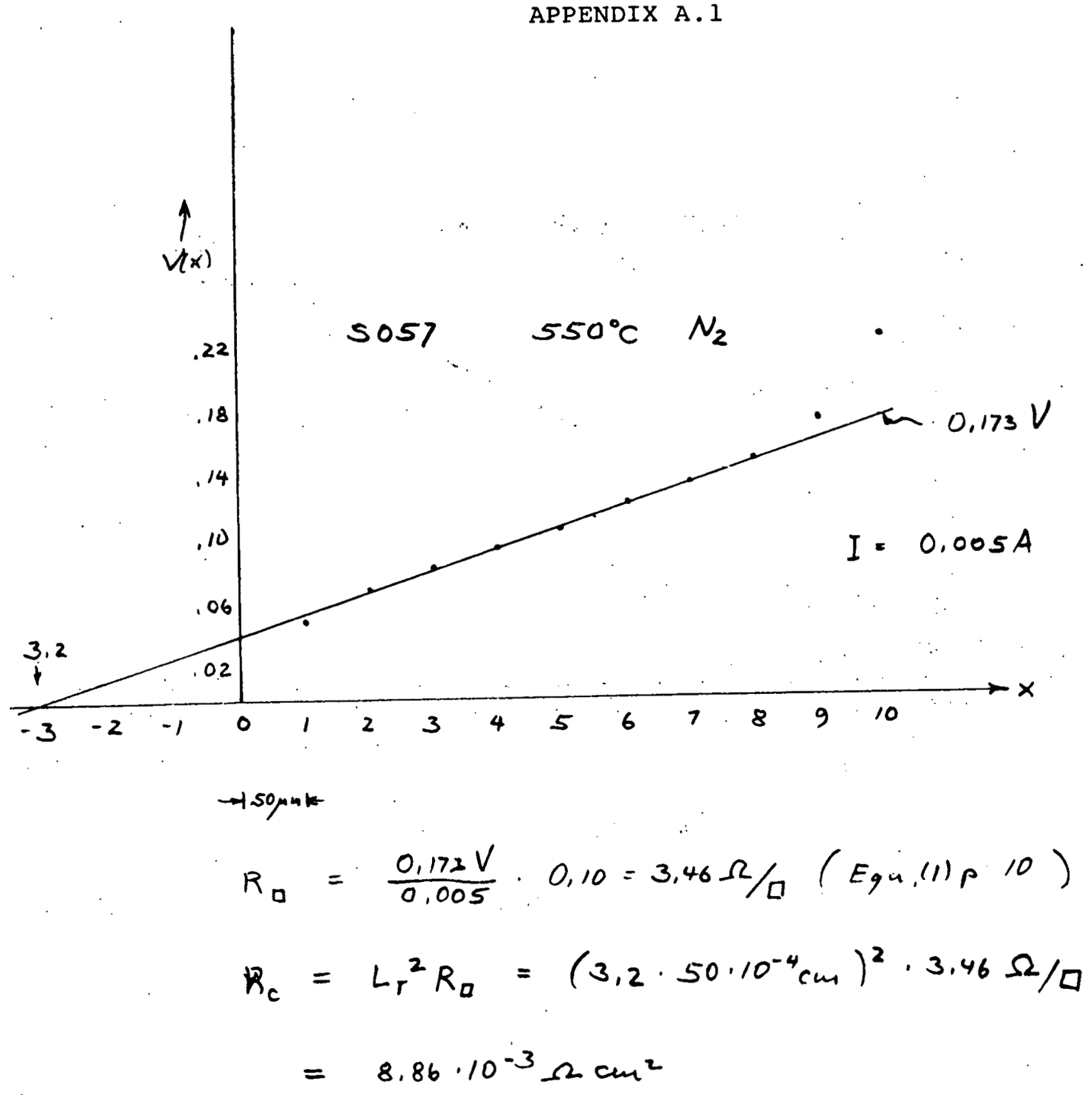

sample plot + contact resistance calculation

Page 40 


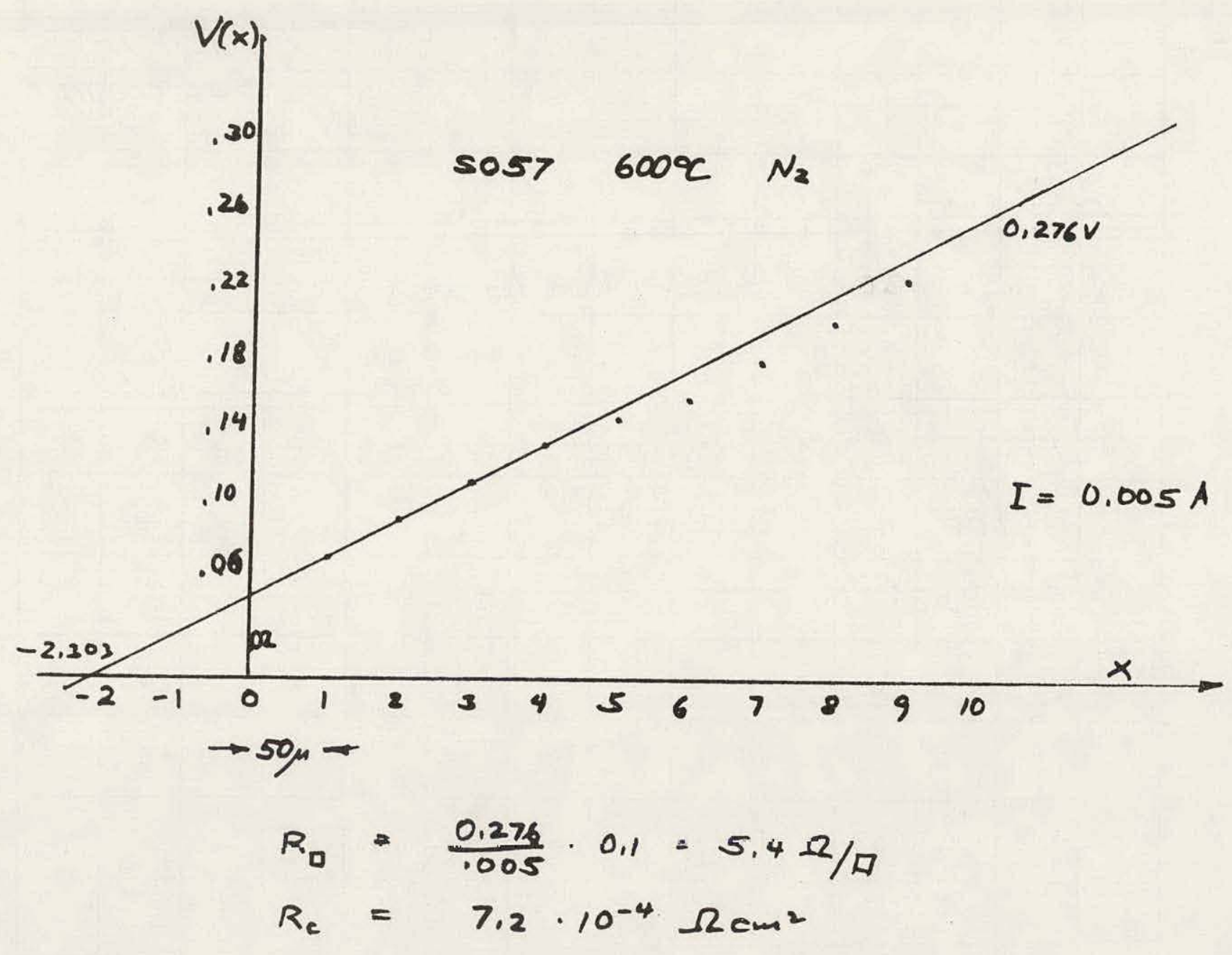




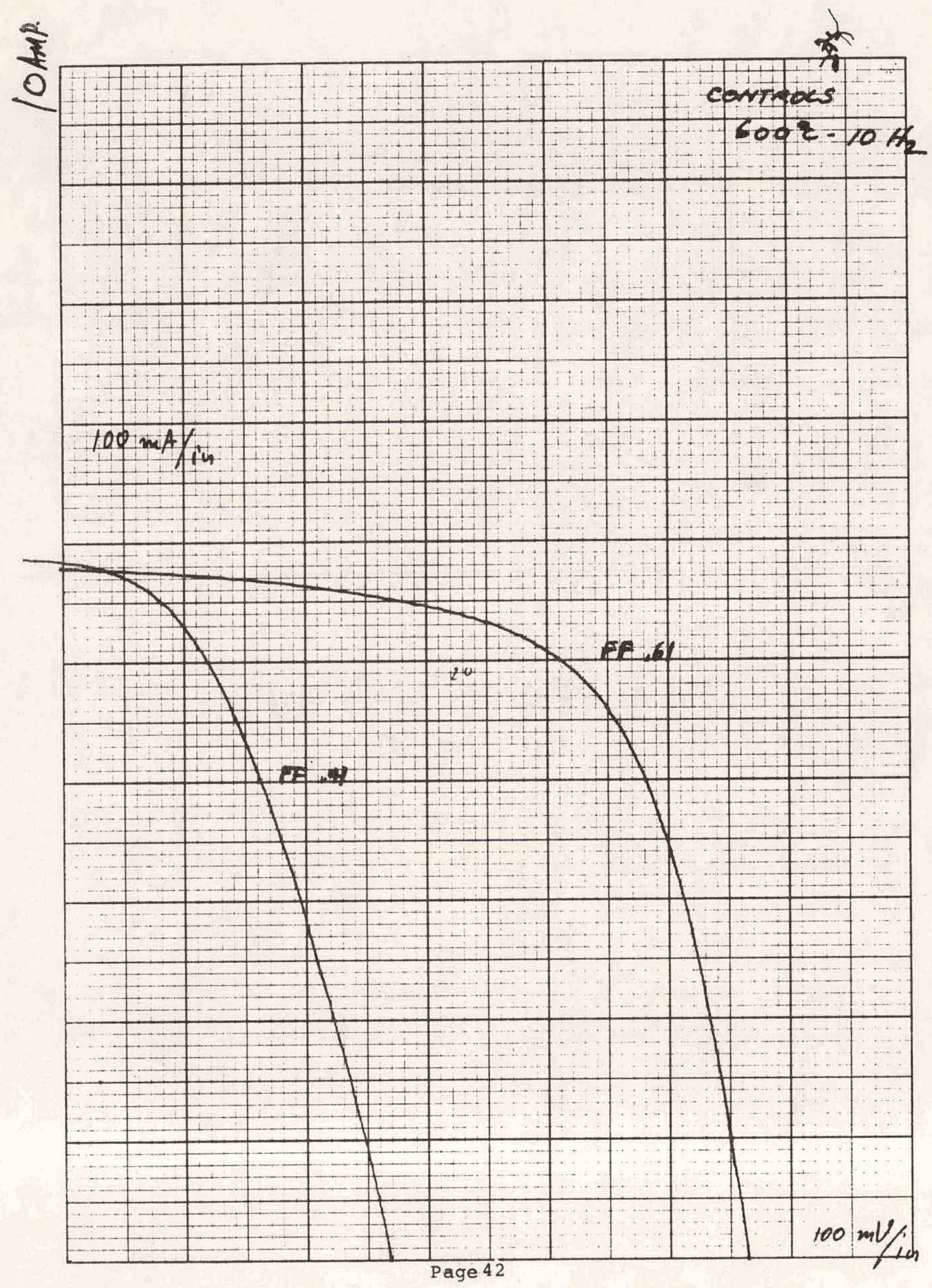




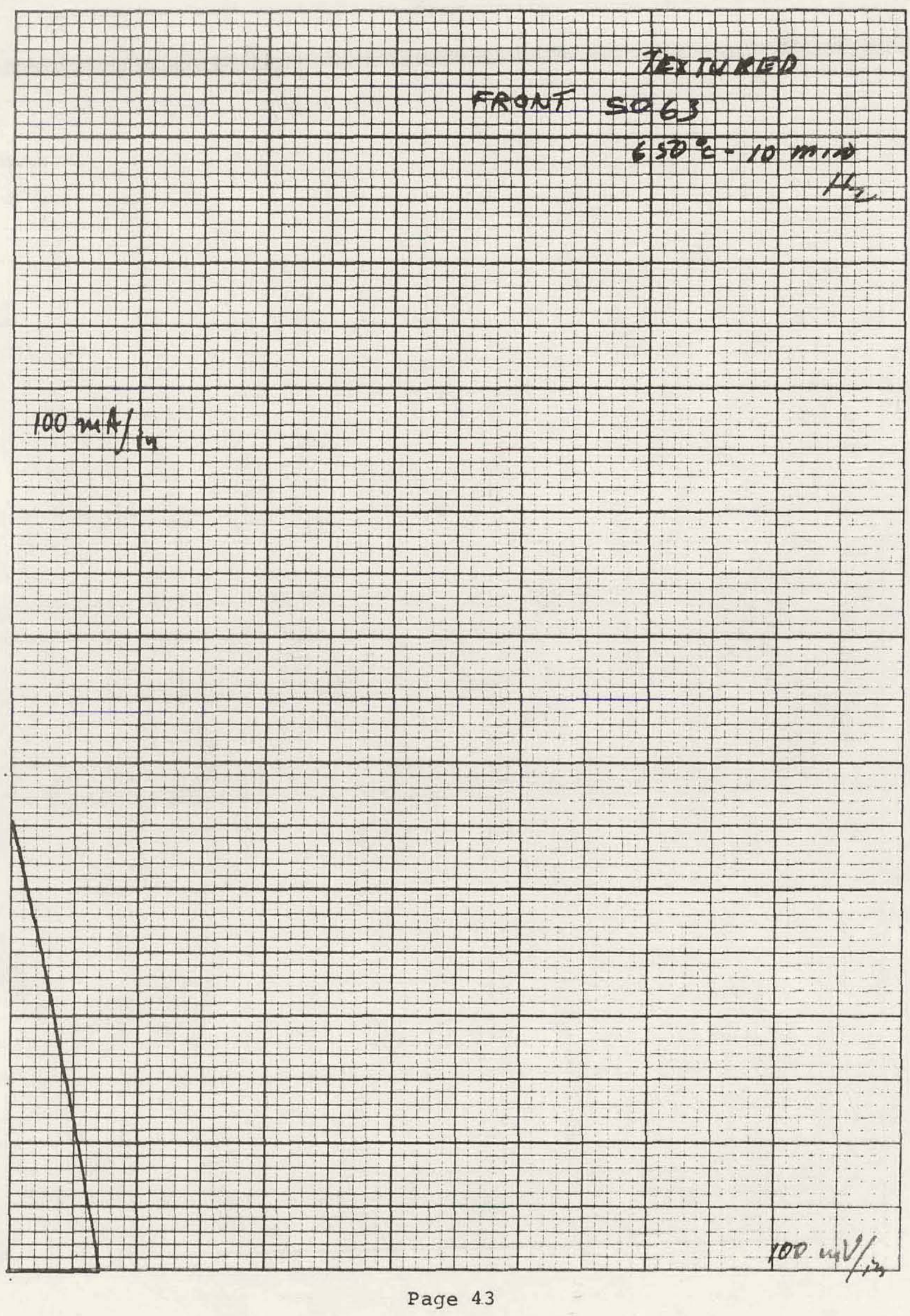




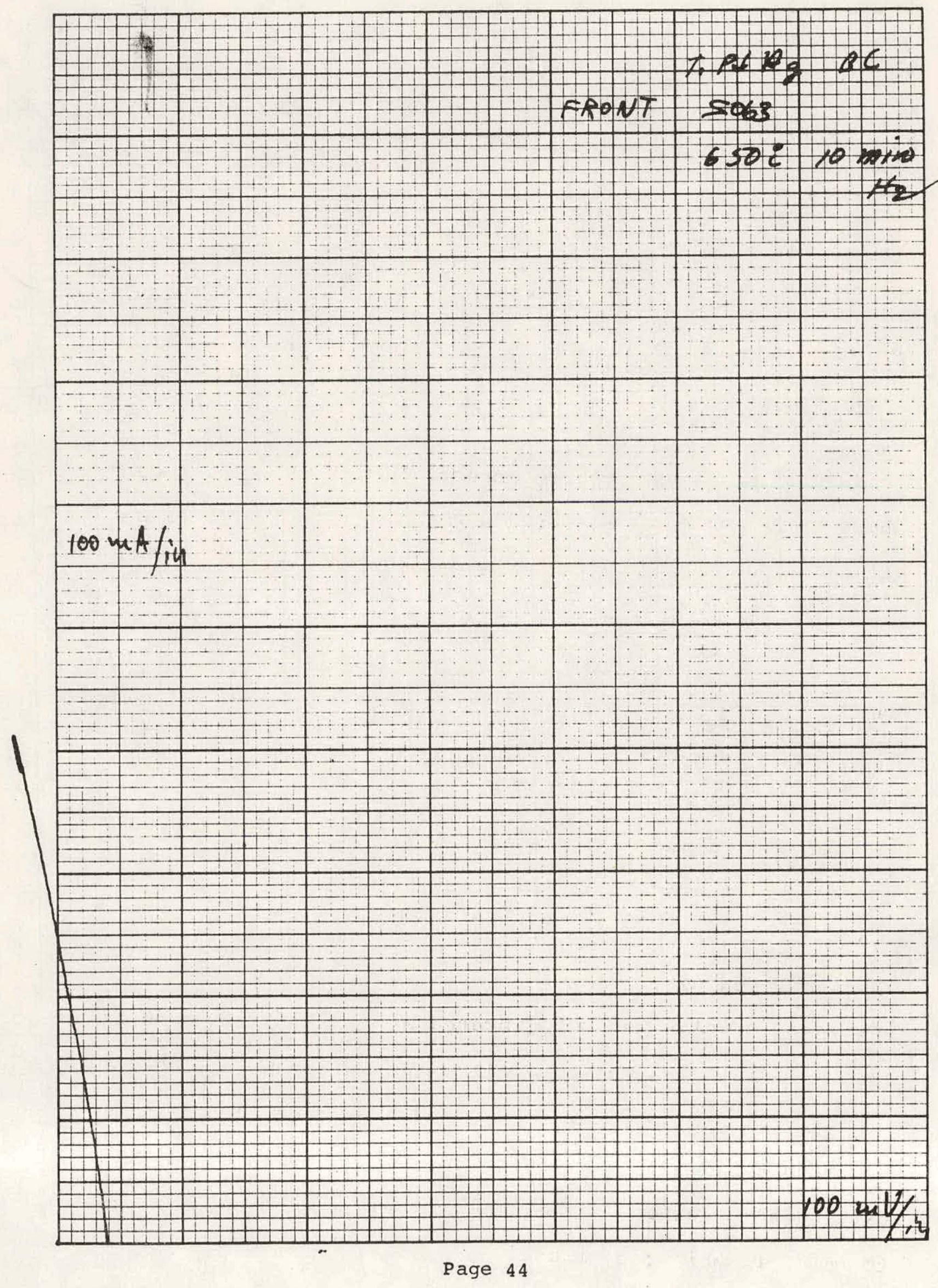




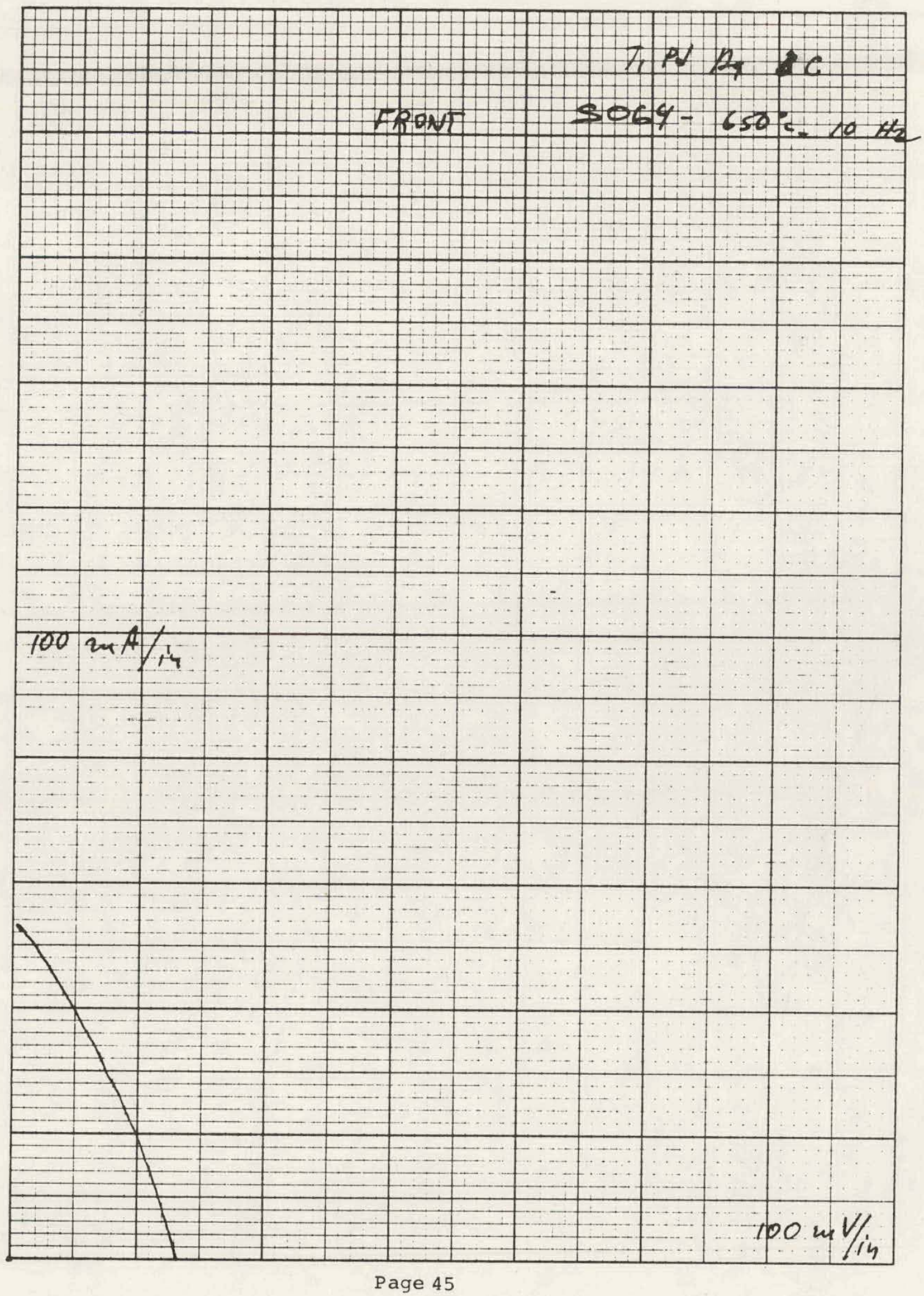




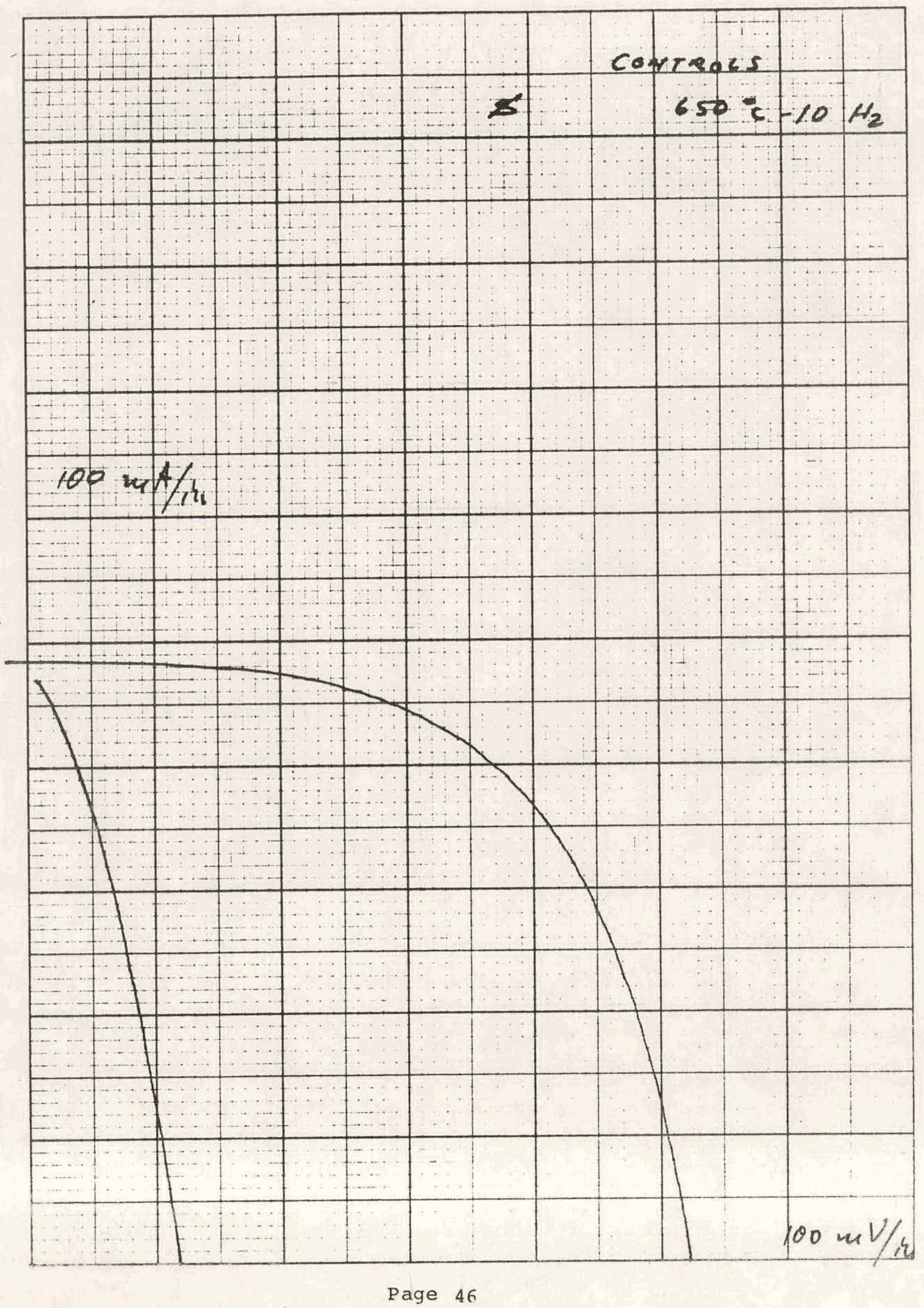




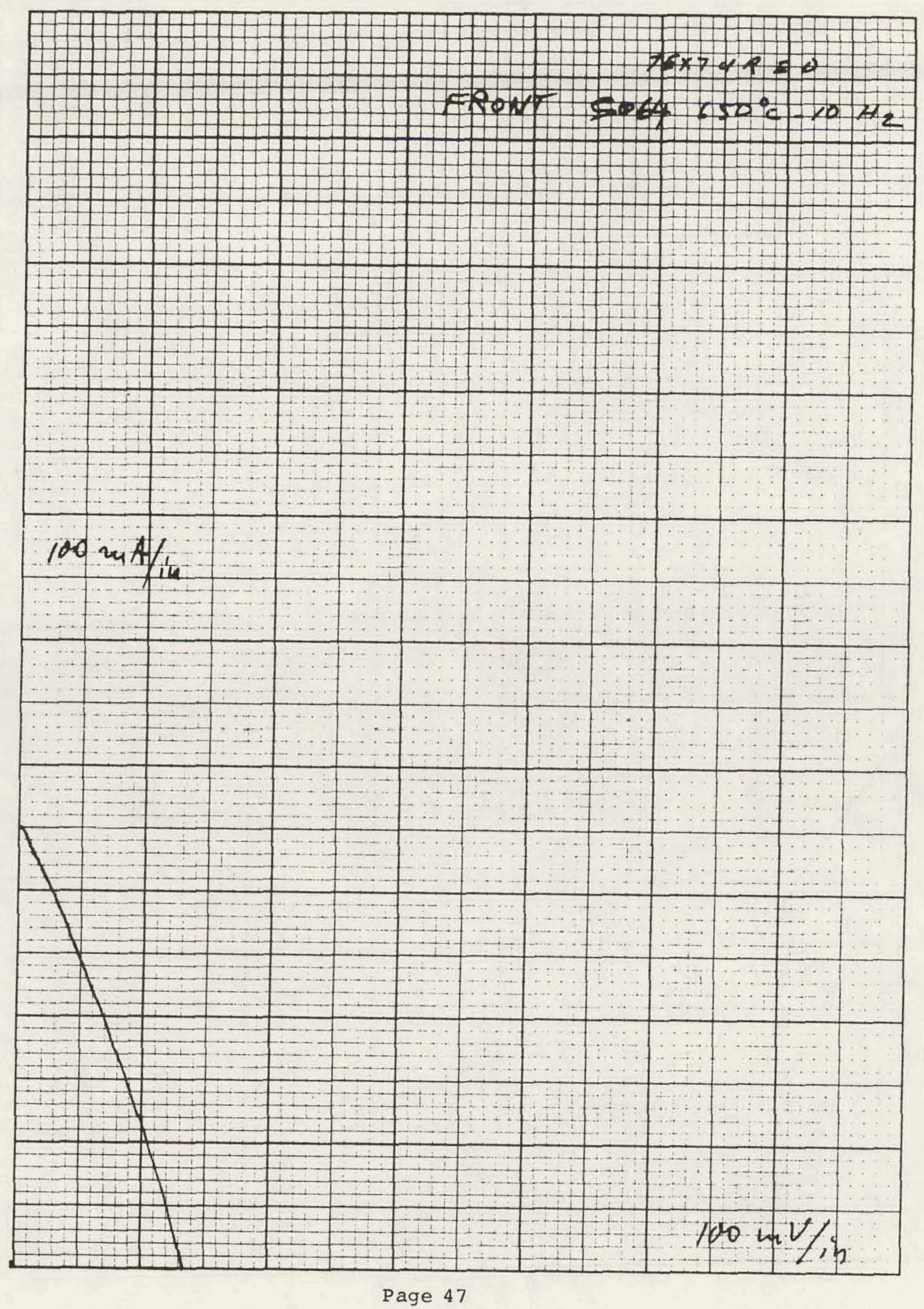




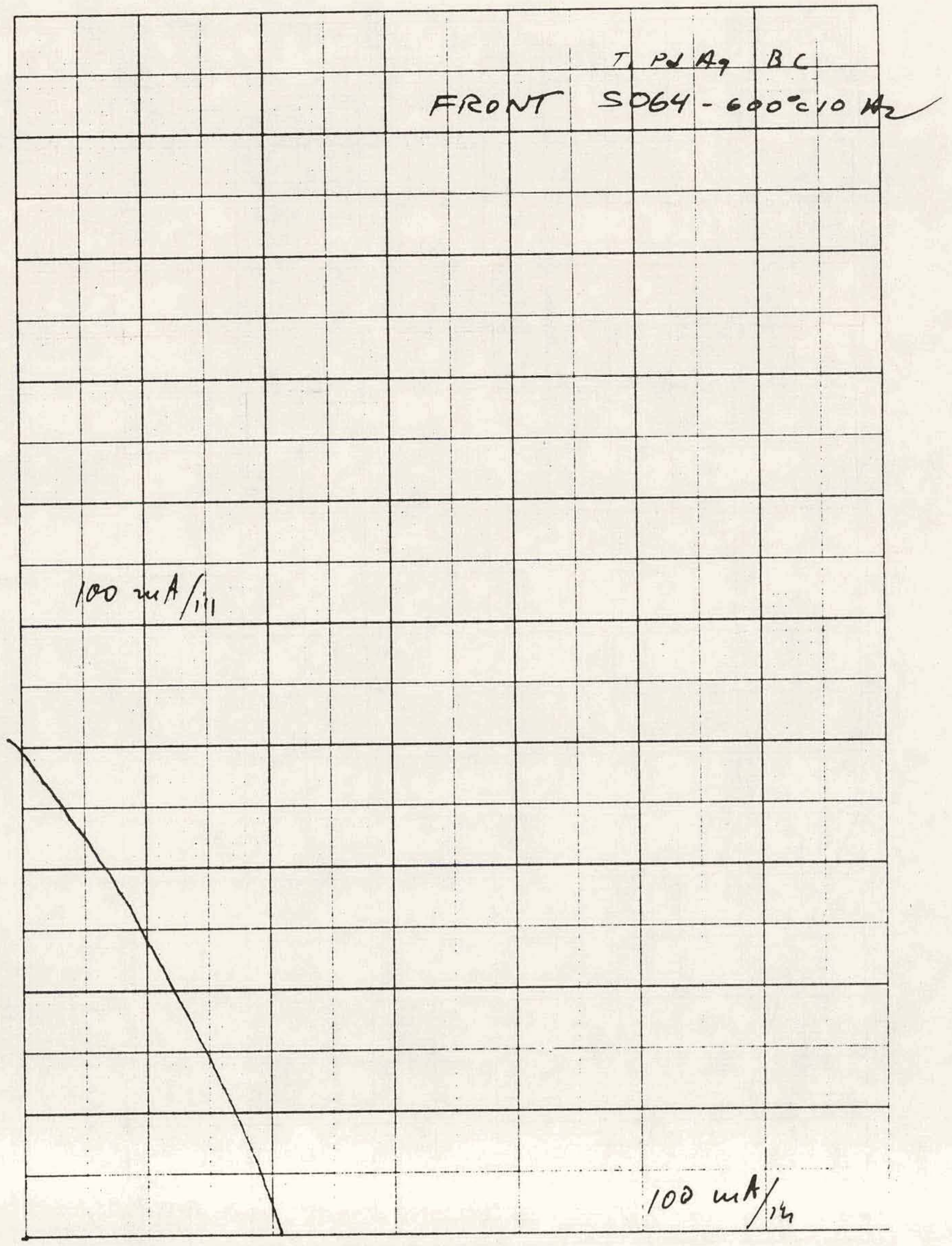

Page 48 


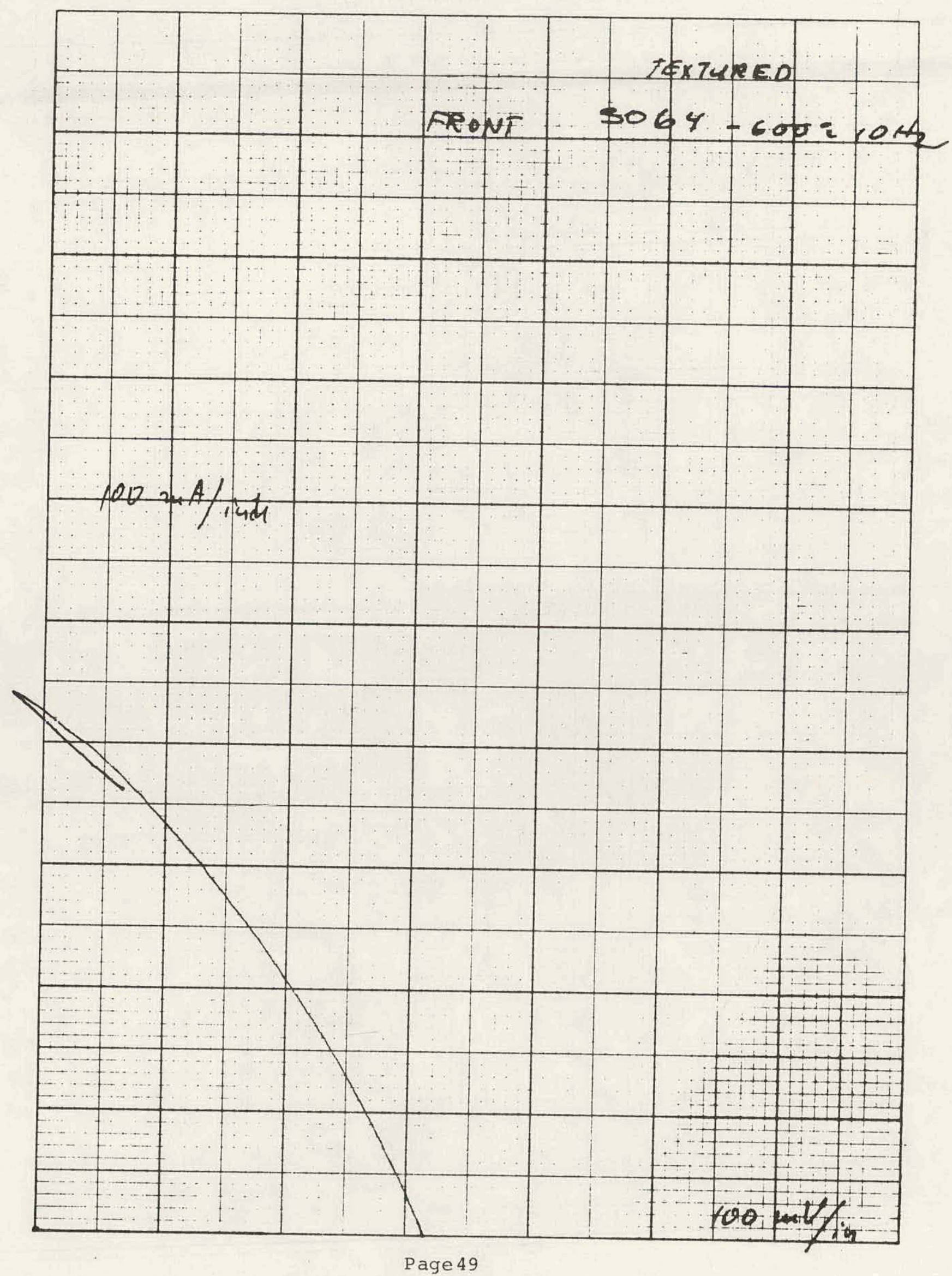




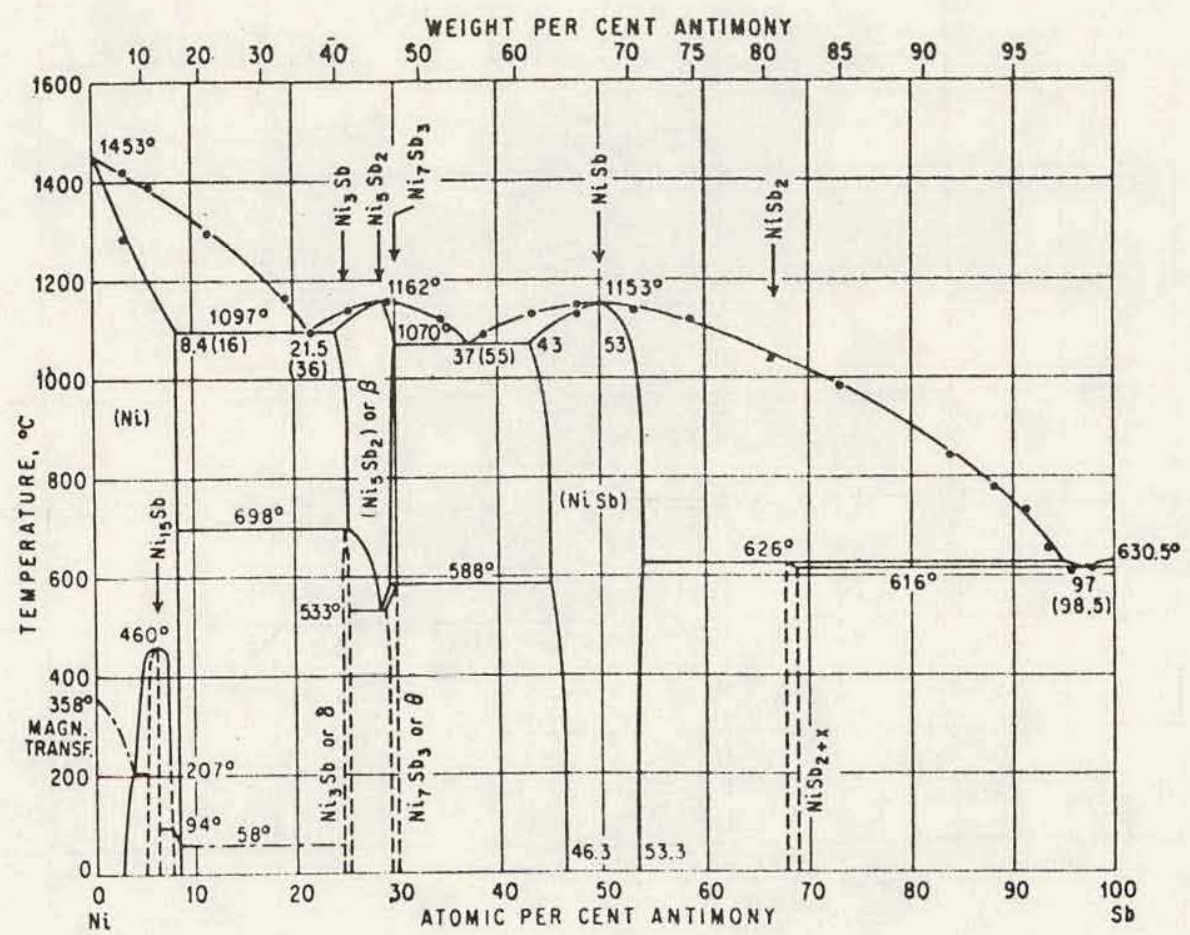

Fig. 36. Equilibrium Phase Diagram of NickelAntimony System.

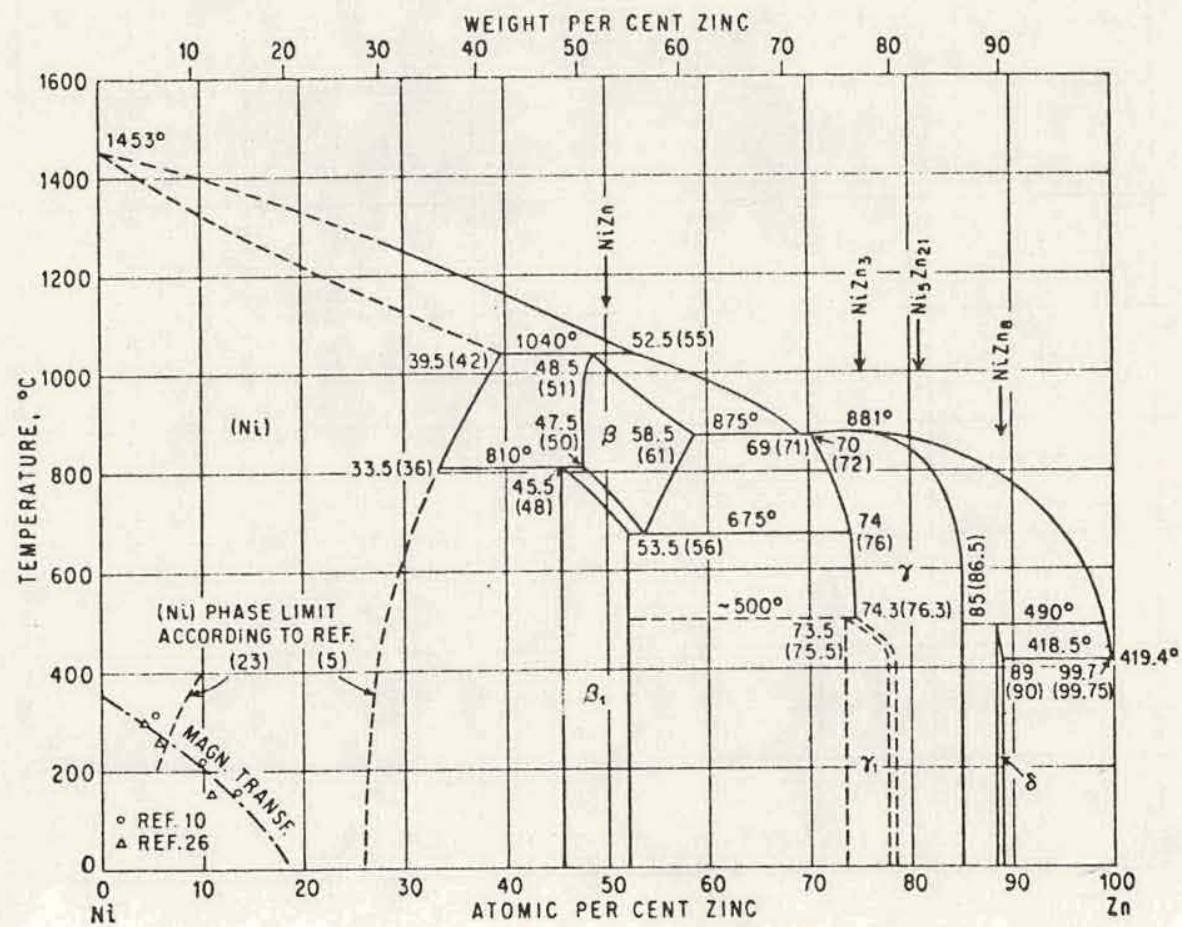

Fig. 37. Equilibrium Phase Diagram of Nickel-Zinc

Page 50 


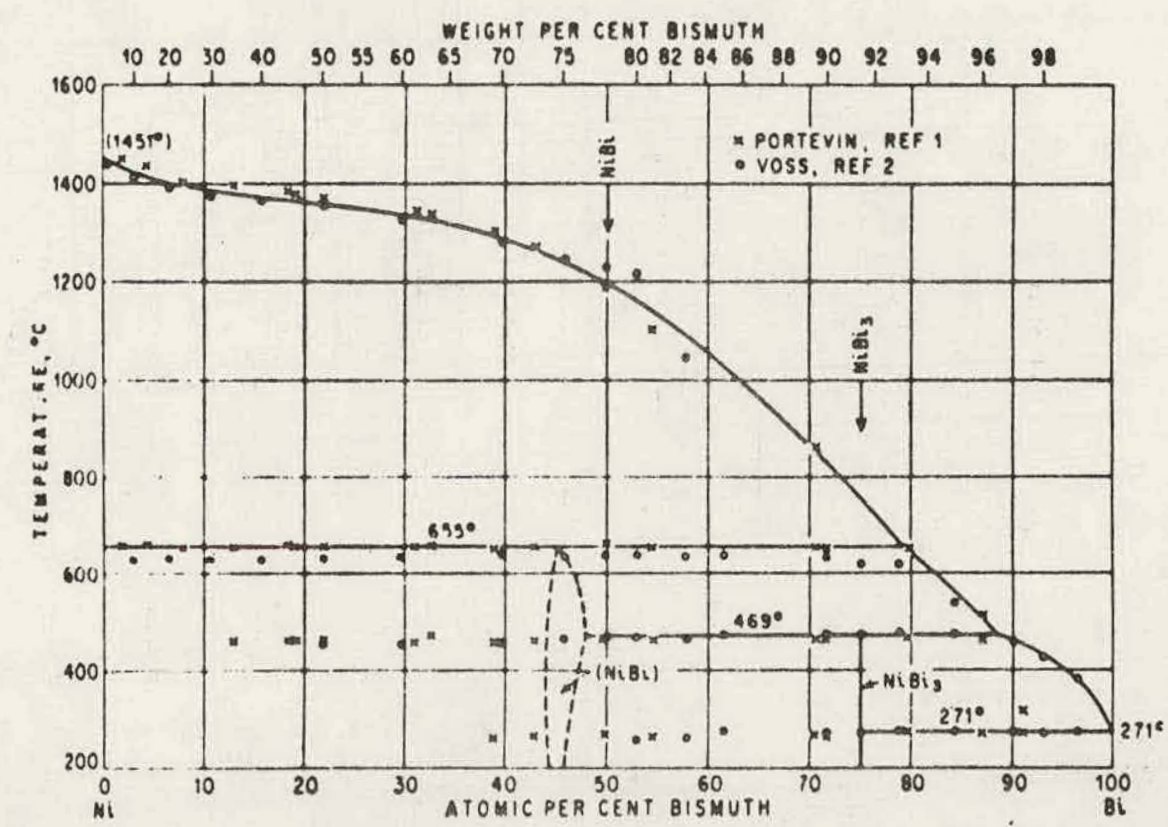

Fig. 38. Equilibrium Phase Diagram of Nickel-Bismuth.

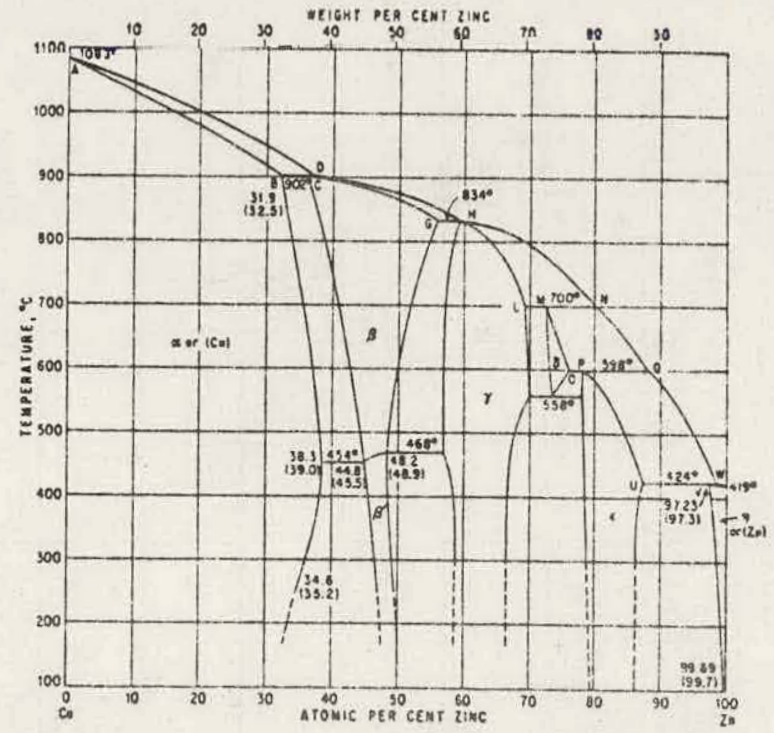

Fig. 39. Equilibrium Phase Diagram of Copper-zinc. 


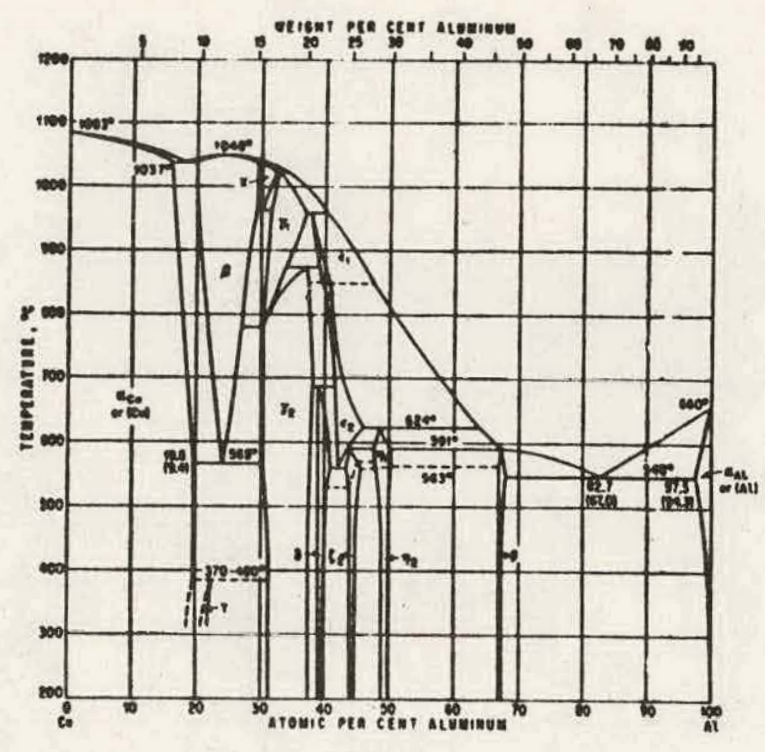

Fig. 40. Equilibrium Phase Diagram of Copper-Aluminum system.

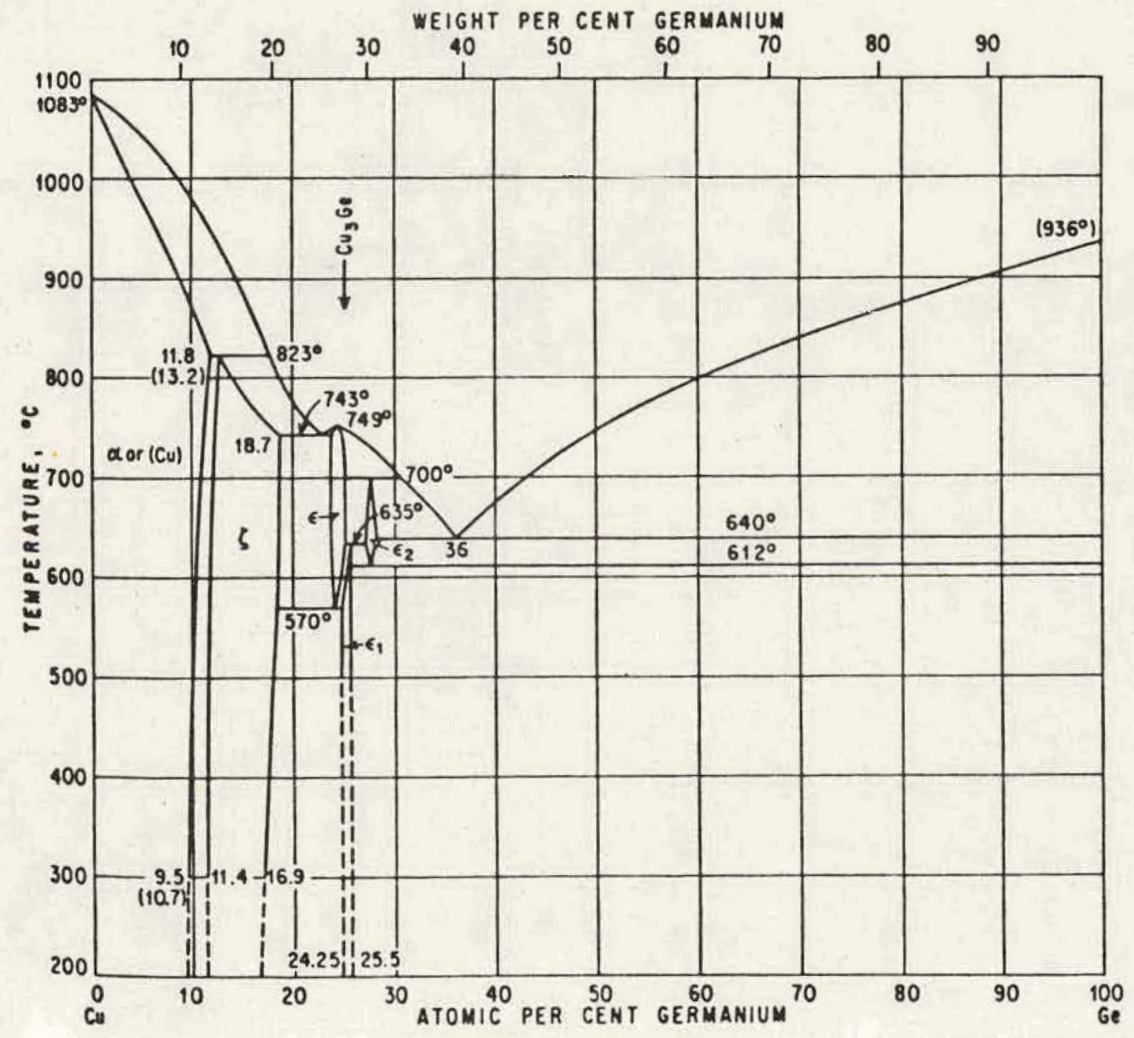

Fig. 41. Equilibrium Phase Diagram of Copper-Germanium system. 


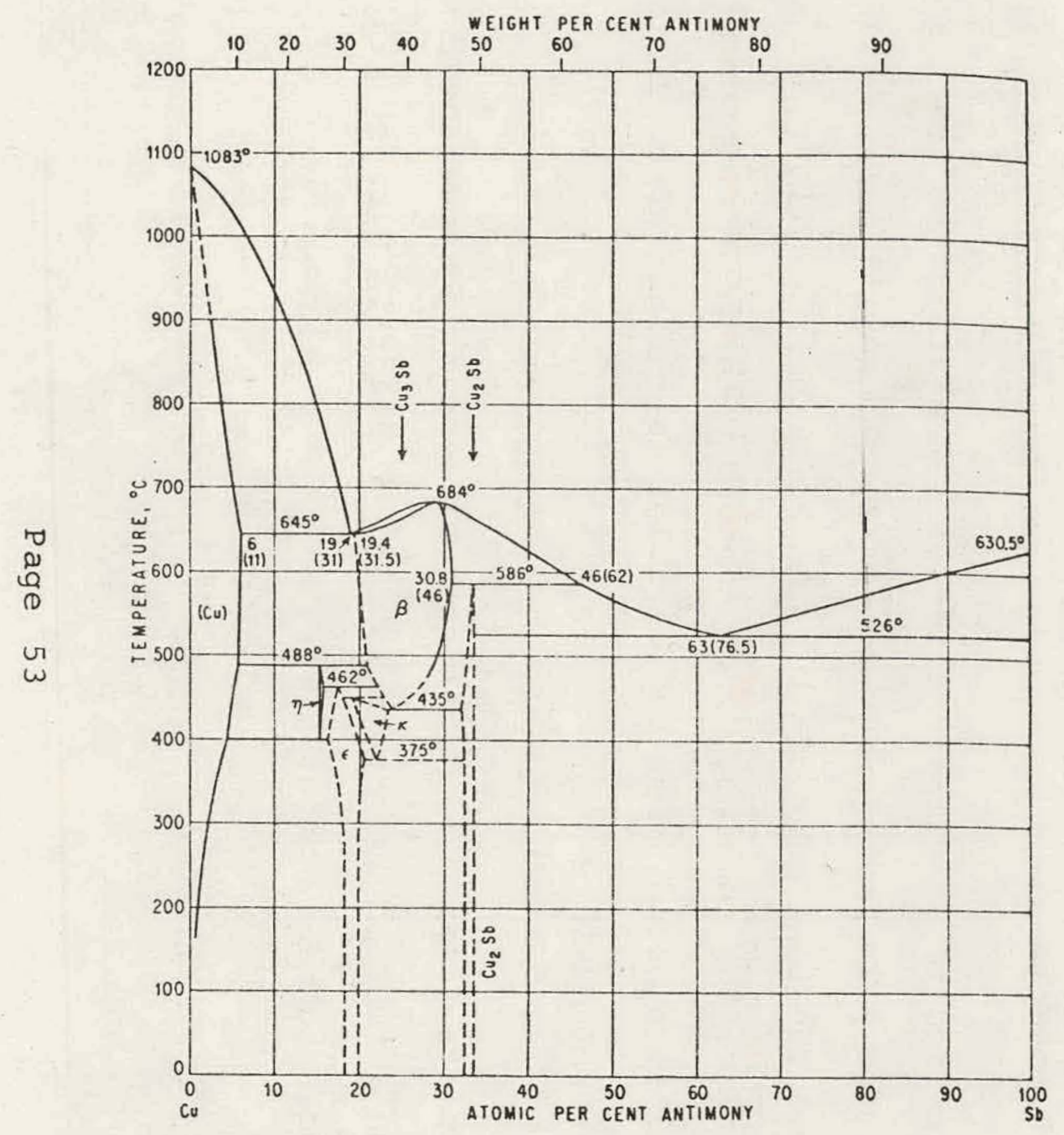

Fig. 42. Equilibrium Phase Diagram of Copper-Antimony System.

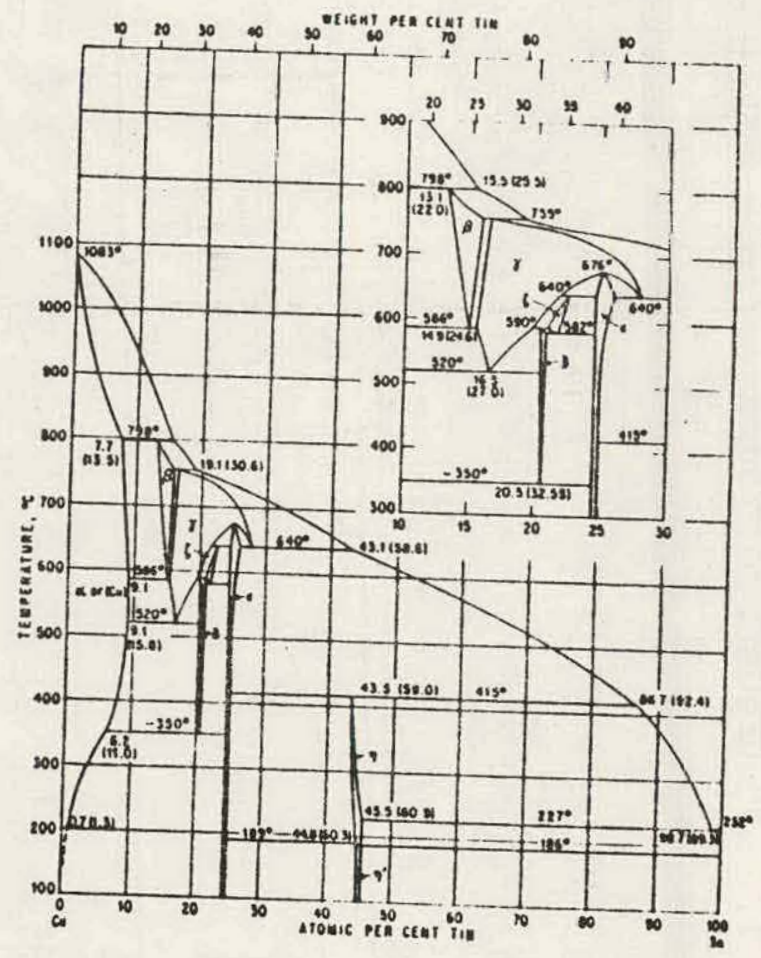

Fig. 43. Equilibrium Phase Diagram of Copper-Tin System. 


\section{APPENDIX A.4 Milling Procedure For All Metal Pastes}

\section{Materials}

An Anthony four-by-eight three roller mill is used in this procedure. Auxiliary tools are a single edge razor blade, a stainless steel spatula, an elastomer squeegee $21 / 2^{\prime \prime} \times 21 / 2^{\prime \prime}$, 4" diameter bowl, 6" Petri dish with cover, grind gage.

\section{Procedure}

(1) A four inch bowl is used for the metal powder, low melting metal frit and vehicle.

(2) The silver fluoride is taken from the hermetically sealed bottle just prior to milling and placed into a 6" Petri dish with cover.

(1) is applied to the first roller with the stainless steel spatula, approximately 25 grams prior to starting the mill. The mill is started. The remainder of (1) is added after the mill is running. The third roller remains out of contact with the second until after the mill is started. The third roller is engaged after 2 minutes of running time.

The endplate separation determines the grinding speed and fineness of grind (other parameters remaining constant). Closest plate distance - coarsest grind. 
The end apron picks up the slurry from the third roller. The metal is bladed back from the third to the first roller. Material thrown or squeezed beyond the endplates is scraped off the turning rollers with the razor blade (after about three minutes of running time).

After about 10 minutes of milling time the fineness of grind is checked by blading on the grind gage. A typical grind number at this point for nickel paste is $\sim 12 \mu \mathrm{m}$ (depending upon a number of parameters including particle size of starting material, roller. speed (1) and spacing, (2) endplate setting, powder-vehicle ratio, etc.)

At 15 minutes milling time the silver fluoride is added to the paste accumulation. This is done by adding $25 \%$ of the total amount of silver fluoride at a time (for instance $x$ times 0.5 grams in a typical composition). The number of silver fluoride additions will depend upon the amount of total ink to be prepared, and the amount of silver fluoride to be added.

(1) Roller \#1 146 RPM

Roller \#2 2180 RPM

Roller \# 3 ఒ800 RPM

(2) Roller adjustment: Generally when the rollers are too close (tight adjustment), the paste tends to run beyond the endplates. When the roller spacing ìs too large (loose adjustment) the paste tends to run between rollers as a visibly unequal bead. Also the paste transport between rollers is too rapid - bead loss between rollers. 
A typical mill run takes about 30-35 minutes including mill stopping times. At the end of the milling run the material on the rollers is scraped off, in addition to the paste on the apron and on the endplates. This material is added to the milled end product. A final grind size check should be made on the grind gage with possible remilling if the grind is too coarse or the distribution too" wide.

Mill cleanup is done by washing all paste exposed parts of the mill with toluene or a suitable substitute solvent (for instance 3 to $5 \%$ toluene in kerosene).

It has been noticed that miliing of silver fluoride may result in dark stains on the surface of the steel roller. This can be minimized by use of dry raw material, extreme low humidity conditions during milling, the use of stainless steel rollers or alumina faced rollers. 


\section{REFERENCES}

1. A. Uhlir Jr., Bell syst. Techn. Journ. 34, 105 (Jan 1955)

2. H.J. Hovel, Semiconductors and Semimetals, R.K. Willardson \& A.L. Beer, Editors, Vol. II, p. 64, Academic Press (1975)

3. L.D. Swanson and L.W. Schmidt, Hoffman Semiconductor Division Publication (1960)

4. Hower, Hooper, Cairns, Fairman and Tremore in Semiconductors and Semimetals, Volume 7 Part A, p. 178-183, Academic Press (197)

5. B. Ross Final Report Automated Array Assembly Task DOE/JPL 955164-79/7 p. 38 (Apr 1979)

6. B. Ross Final Report Automated Array Assembly Task DOE/JPL 955164-79/7 p. 36 (Apr 1979)

7. M. Hansen and $\mathrm{K}$. Anderko "Constitution of Binary Alloys", 2nd Edition McGraw-Hill, New York, N.Y. (1958)

8. C. B. Collins and R.O. Carlson, Phys. Rev. 108, 1409 (1957)

9. B. Ross and J.R. Madigan, Phys. Rev. 108, 1428 (1957)

10. R.H. Hopkins, J.R. Davis, P.D. Blais, A. Rohatgi, R.B. Campbell, P. Rai-Choudhury, R.E. Stapleton, H.C. Mollenkopf and J.R. McCormick, Fifteenth Quarterly Report, Silicon Materials Task DOE/JPL-954331-79/7, p. 43 (Jul 1979)

11. W.C. Dash, J. Appl Phys. 37, 1193 (1956) 